This is the accepted version of the article published in the final form in

Sustainable Energy \& Fuels, Issue 8, Vol. 4, pages 3879-3883, in 2020

by the Royal Society of Chemistry at

DOI: 10.1039/DOSE00752H.

This article may be used for non-commercial purposes in accordance with RSC Terms and Conditions

\title{
Electrophoretic deposition of supramolecular complexes for the formation of carbon nitride films
}

Received 00th January 20xx,

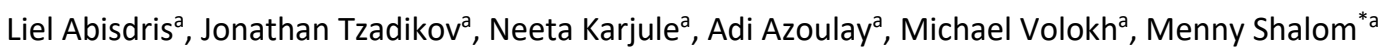

Accepted 00th January 20xx

DOI: $10.1039 / x 0 x \times 00000 x$

The large-scale fabrication of polymeric carbon nitride (CN) films with tunable thickness, composition and photoelectrochemical properties is reported. To do so, we deposited supramolecular complexes as seeding layers prior to a thermal deposition of melamine vapor. The seeding layer is succesfuly formed by employing electrophoretic deposition of the supramolecular complexes on various substartes. The $\mathrm{CN}$ films exhibit good photoelectrochemical activity due to strong adhesion to the substrate, which allows a fast electron transfer and hole extraction to the electrolyte.

Polymeric carbon nitride ( $\mathrm{CN}$ ) has emerged as a promising material for various catalytic reactions, spanning photo-, electro- and organo-catalysis, ${ }^{1-4}$ owing to its tunable band gap, suitable energy bands position, high stability to harsh chemical environment, easy preparation and low cost. ${ }^{5,6}$ However, while meaningful advances have already been achieved in $\mathrm{CN}$ chemistry and utilization as a powder, 7,8 the exploitation of $\mathrm{CN}$ materials in (opto)electronic and photoelectrochemical devices such as photovoltaic cells, light-emitting diodes, and photoelectrochemical cells (PEC) is still at an early stage due to the challenge of depositing uniform and controlled $\mathrm{CN}$ layers on substrates. 9,10 Moreover, for many devices, intimate contact with the substrate surface should be established to enable good electronic conductivity and strong adhesion in a solution.

Recently, several methods, which are based on the direct growth of $\mathrm{CN}$ film or by vapor deposition methods were successfully introduced. ${ }^{11-14}$ Each method possesses several advantages such as controlled optical and chemical properties for the direct growth and substantial control over the homogeneity and thin layer formation for the vapor route. However, despite the achievable control of the vapor method,

\footnotetext{
a. Department of Chemistry and Ilse Katz Institute for Nanoscale Science and Technology, Ben-Gurion University of the Negev, Beer-Sheva 8410501, Israel. Electronic Supplementary Information (ESI) available: detailed experimental section, SEM, FTIR, 3D laser microscopy, layer thickness estimation, XPS, optical characterization, chronoamperometry, Mott-Schottky plots, energy diagram and IPCE measurements. See DOI: 10.1039/x0xx00000x
}

the surface wettability and chemical structure strongly affect the resulting layer quality and thickness. Moreover, vapor methods endow great control of the thickness up to several hundred nanometers, while for some applications, a much thicker layer is required.

Electrophoretic deposition (EPD) is considered as an easy, scalable and benign method to deposit various nano- and microscale objects ranging from ceramics, ${ }^{15}, 16$ through carbon nanostructures, ${ }^{17,} 18$ to metal and semiconductor nanoparticles of various shapes, ${ }^{19-23}$ metal-organic frameworks, ${ }^{24,} 25$ powders of single-source molecular precursors ${ }^{26}$ and so forth. In EPD, the electrophoresis phenomenon is used to deposit charged particles from a suspension using an external electric field $(E)$. Our group and others described the formation of $\mathrm{CN}$ films through EPD. ${ }^{27}$ Nevertheless, despite the successful deposition of $\mathrm{CN}$ nanosheets, the large size of the $\mathrm{CN}$ sheets along with their low solubility in common solvents resulted in a poor physical connection to the substrate's surface, which strongly hinders the electronic conductivity from the layer to the conductive substrate.

Here we report the large-scale fabrication of $\mathrm{CN}$ films by using supramolecular assemblies composed from $\mathrm{CN}$ monomers as a seeding layer for the deposition of melamine vapor. For the growth of the seeding layer, we used EPD to deposit cyanuric acid-melamine supramolecular complexes. ${ }^{28}$ This new deposition method enables good control over the $\mathrm{CN}$ thickness as well as its photophysical and structural properties. The CN films exhibit good photoelectrochemical activity owing to a strong adhesion to the substrate and the formation of an electronic heterojunction. We believe this is one of the synthetic tools that can be harnessed to allow fabrication of metal-free CN-based photoanodes for PEC.

An illustration of the fabrication of the $\mathrm{CN}$ electrode by using an EPD method assisted by vapor deposition is presented in Scheme 1. First, cyanuric acid-melamine (CM) supramolecular complexes were prepared by mixing the precursors in water 


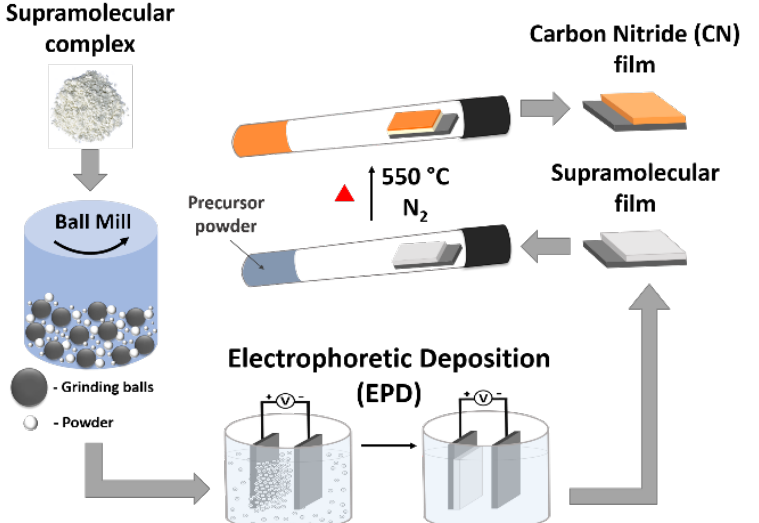

Scheme 1 Illustration of the preparation of CN films on FTO substrates by therma condensation of supramolecular films.

(1:1 molar ratio), resulting in a powdery precipitate. ${ }^{29} \mathrm{~A}$ stable colloidal suspension for EPD was obtained by ball-milling the $\mathrm{CM}$ powder to ensure dispersion and narrower size distribution in toluene as the dispersion medium.

Homogenous white CM complexes were deposited on FTOcoated glass substrates via EPD by applying a constant potential bias of $300 \mathrm{~V}$ between the two electrode substrates, dipped in the suspension, for varying time periods $(5,30,60,120$ and 180 s). Ball-milled (bm) CM particles were deposited on the positively-biased electrode, which indicates that the CM colloids are negatively charged (visualized in Movie S1 "EPD process of bm-CM complex").

Scanning electron microscopy (SEM) images show that the rod-like structure of the $\mathrm{CM}$ powder assembled in water has completely changed after ball milling, ${ }^{30}$ which resulted in nanometric-sized particles that assembled into aggregates (Fig. $\mathrm{S} 1$ in the ESI). SEM top-view images of the $\mathrm{CM}_{x}$ electrodes (Fig. 1 a, where $x$ represents the deposition time in s) show how the aggregates are successfully deposited on FTO glass (Fig. $1 \mathrm{~b}$ and Fig. S2).

The preservation of the CM supramolecular complexes' structure after deposition on FTO was confirmed by X-ray diffraction (XRD) and Fourier-transform infrared (FTIR) analyses. Compared to the CM powder, XRD patterns of the bm-CM powder as well as $\mathrm{CM}_{120}$ electrode (which was chosen as a case study due to its enhanced photoelectrochemical performance as will be discussed later) display two broader peaks, at $2 \theta=$ $10.67^{\circ}(100)$ and $27.9^{\circ}$ (002) (Fig. 1c), attributed to in-planar packing and graphite-like stacking, respectively. ${ }^{31}$ The reduction of diffraction signals around $27^{\circ}$ after ball-milling indicates that the CM particles are more orientated to one direction. ${ }^{32}$ The typical peaks in the FTIR spectra of $\mathrm{CM}$ arising from the $\mathrm{C}=\mathrm{O}$ vibration peaks at $1656 \mathrm{~cm}^{-1}$ and $1725 \mathrm{~cm}^{-1}$, and the triazine ring vibration peak at $763 \mathrm{~cm}^{-1}$ (Fig. S3), further support the successful CM film formation on FTO.

Altering EPD times allowed control over the film thickness (Fig. 1d and Fig. S4). A clear correlation between the film thickness and the deposition time is observed for time intervals shorter than $60 \mathrm{~s}$; it is further supported by preparation of three additional $\mathrm{CM}$ electrodes: $\mathrm{CM}_{2,15,45}$ (Fig. S5). Once deposition time reaches $60 \mathrm{~s}$, the average film thickness stabilizes around (a) $1 \mathrm{~cm}$

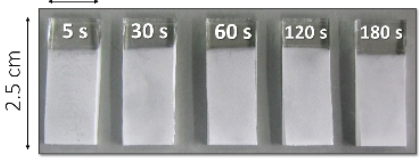

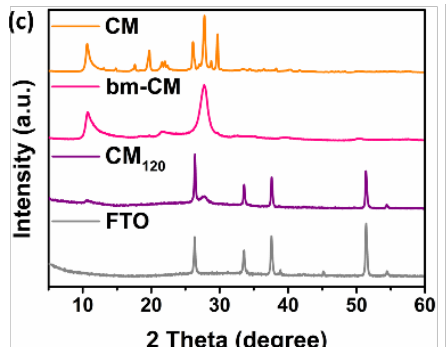
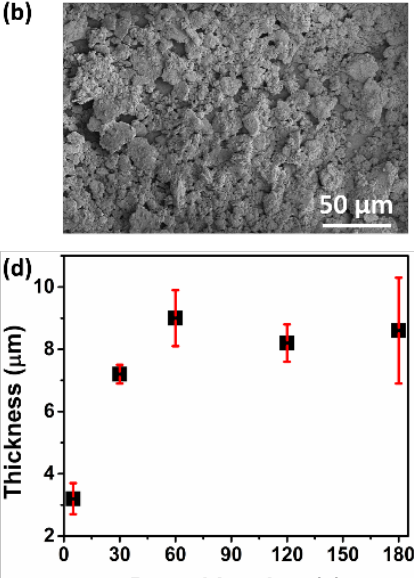

Fig. 1 (a) Digital image of $\mathrm{CM}_{x}$ electrodes (where $x$ is the deposition time, 5-180 s). (b) Top-view SEM image of $\mathrm{CM}_{120}$ electrode. (c) XRD patterns of CM powders (assembled in water) before (orange) and after (pink) ball-milling, a $\mathrm{CM}_{120}$ electrode (purple) and a clean FTO reference (gray). (d) Film thickness of $\mathrm{CM}_{x}$ electrodes as function of deposition time, determined by laser microscopy (see details in Fig. S4 and Table S1).

8.7 $\mu \mathrm{m}$ (Table S1) as aggregates start falling from the substrate, at the end of the deposition, as the electrode is pulled out of the suspension (visualized in Movie S1). The maximum measured thickness is approximately $10 \mu \mathrm{m}$ (top of the error bars). From these measurements we conclude that $120 \mathrm{~s}$ is the optimal deposition time, as $\mathrm{CM}_{120}$ displays a relatively thick film with small standard deviation. Once the control over the supramolecular film thickness was established, this film was applied as the seeding layer in order to form $\mathrm{CN}$ films upon thermal condensation.

$\mathrm{CN}$ electrodes were formed by heating the $\mathrm{CM}_{x}$ electrodes at $550^{\circ} \mathrm{C}$ under $\mathrm{N}_{2}$ atmosphere together with $1.0 \mathrm{~g}$ of melamine powder (M), at the closed edge of the tube without direct contact with the $\mathrm{CN}$ electrode (Scheme 1). During calcination, $M$ vapor is deposited on the formed $\mathrm{CM}$ films, which act as nucleation centers (i.e., a seeding layer) for the growth of the final $\mathrm{CN}$ films. In this manner, uniform yellow $\mathrm{CN}$ films were obtained on top of the FTO (Fig. 2a), labeled as $\mathrm{CN}^{-\mathrm{CM}_{x} \mathrm{M}}$ electrodes. The addition of $\mathrm{M}$ as a $\mathrm{CN}$ precursor displays a crucial role, as in its absence only a very thin $\mathrm{CN}$ film was formed, and most of the supramolecular film has evaporated completely during the thermal treatment.

SEM images of $\mathrm{CN}-\mathrm{CM}_{120} \mathrm{M}$ electrode (Fig. $2 \mathrm{~b}-\mathrm{c}$ ) as well as top-view SEM images of $\mathrm{CN}-\mathrm{CM}_{x} \mathrm{M}$ electrodes (Fig. S6) show the attachment of large $\mathrm{M}-\mathrm{CN}$ features on top of the film as a result

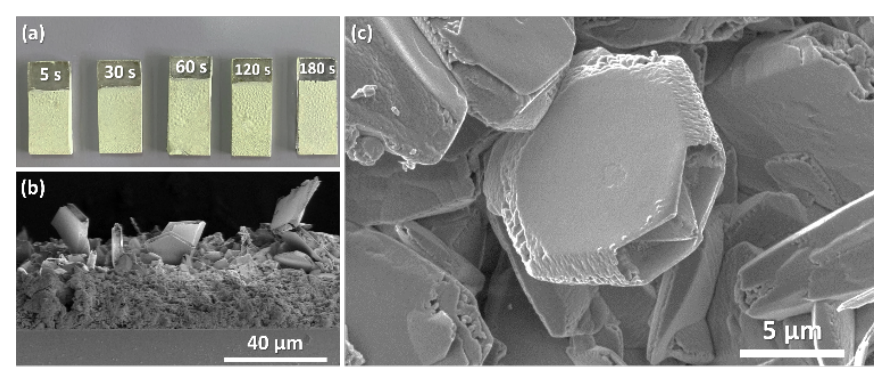

Fig. $2 \mathrm{CN}$ films formed after a thermal treatment. (a) Digital photo of the final $\mathrm{CN}-\mathrm{CM}_{x} \mathrm{M}$

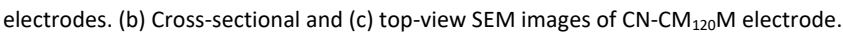


of melamine vapor deposition. Cross-sectional SEM images of $\mathrm{CN}-\mathrm{CM}_{x} \mathrm{M}$ electrodes suggest the formation of a compact film with a strong adhesion of the CN to the FTO (Fig. S7a).

High-magnification cross-sectional SEM images of CN$\mathrm{CM}_{120} \mathrm{M}$ electrode show the direct growth of the $\mathrm{CN}$ film on top of the FTO coating ( $350 \mathrm{~nm}$ ) without evidence of the formation of two different layers (Fig. S7b-c). The latter implies that the $\mathrm{CM}$ film mainly provides a seeding layer for the growth of $\mathrm{CN}$ films.

To clarify the importance of the addition of $M$ powder as well as to show that the supramolecular film acts as a seeding layer for the formation of $\mathrm{CN}$ films, $\mathrm{CM}_{60}$ (the thickest supramolecular film) without the addition of $\mathrm{M}$ powder and a bare FTO electrode with $1.0 \mathrm{~g}$ of $\mathrm{M}$ powder were subjected to the same calcination procedure as the $\mathrm{CN}-\mathrm{CM}_{x} \mathrm{M}$, and were labeled $\mathrm{CN}-\mathrm{CM}_{60}$ and $\mathrm{CN}-\mathrm{M}$, respectively. SEM images of $\mathrm{CN}-$ $\mathrm{CM}_{60}$ (Fig. S8a) show a very poor $\mathrm{CN}$ coating on the FTO, while $\mathrm{CN}-\mathrm{M}$ exhibits a highly disordered coating with flower-like microstructures ${ }^{33}$ of calcined melamine directly on top of the FTO (Fig. S8b). These results emphasize the synergetic effect of the seeding layer together with a $\mathrm{CN}$ precursor in order to grow CN films.

XRD patterns of $\mathrm{CN}-\mathrm{CM}_{x} \mathrm{M}$ show a strong peak attributed to the interplanar stacking (002) peak at $27.5^{\circ}$ and a relatively weak in-planar (100) peak at around $13.4^{\circ}$ (Fig. 3a), both correspond to the structure of layered polymeric $\mathrm{CN}$ materials. FTIR spectra reveal stretching modes of $\mathrm{CN}$ heterocycles in the $1200-1600 \mathrm{~cm}^{-1}$ range, while the peak at $800 \mathrm{~cm}^{-1}$ is attributed to the breathing vibration of the tri-s-triazine unit and the peak at around $3000 \mathrm{~cm}^{-1}$ belongs to $\mathrm{N}-\mathrm{H}$ stretching (Fig. 3b) confirming the formation of $\mathrm{CN}$ films.

C1s XPS spectra (Fig. S9a) of $\mathrm{CN}-\mathrm{CM}_{120} \mathrm{M}$ electrode presents two different species corresponding to adventitious $\mathrm{C}-$ $\mathrm{C}$ and $\mathrm{N}=\mathrm{C}-\mathrm{N}$ coordination at $284.8 \mathrm{eV}$ and $288.1 \mathrm{eV}$, respectively. N1s XPS spectra (Fig. S9b) support the CN formation as four deconvoluted peaks at $398.5 \mathrm{eV}, 399.8 \mathrm{eV}$, $401.2 \mathrm{eV}$ and $404.2 \mathrm{eV}$ correspond to $\mathrm{C}=\mathrm{N}-\mathrm{C}, \mathrm{N}-\mathrm{C}_{3}, \mathrm{C}-\mathrm{NH}_{2}$ and charging effects, respectively.

The final $\mathrm{CN}$ film thickness was affected by varying the deposition time of the supramolecular assemblies (Fig. 3c, Fig. S10 and Table S2). The same trend that was observed in CM films can be seen also in the $\mathrm{CN}-\mathrm{CM}_{x} \mathrm{M}$ electrodes, excluding $\mathrm{CN}$ $\mathrm{CM}_{180} \mathrm{M}$, which was significantly thicker than the other electrodes, probably due to the high roughness of its seeding layer (expressed by the large standard deviation of the $\mathrm{CM}_{180}$ film). In order to investigate the effect of melamine vapor deposition during the calcination of the seeding layer, $\mathrm{CM}_{60}$ electrodes with different amounts of melamine powder (0.2, $0.4,0.6$ and $0.8 \mathrm{~g}$ ) were prepared. Thicker $\mathrm{CN}-\mathrm{CM}_{60} \mathrm{M}_{y}$ films (where $y$ represents the melamine mass in $\mathrm{g}$ ) were obtained in almost a linear manner when a higher melamine powder mass was presented in the reaction tube (Fig. S11 and Table S3).

The EPD process enables an easy scaled-up formation of $\mathrm{CN}$ films assisted with melamine sublimation during calcination. As exemplified in Fig. 3d, a large CN film was deposited on $1 \times 9$ $\mathrm{cm}^{2}$ (width $\times$ length) FTO. (a)
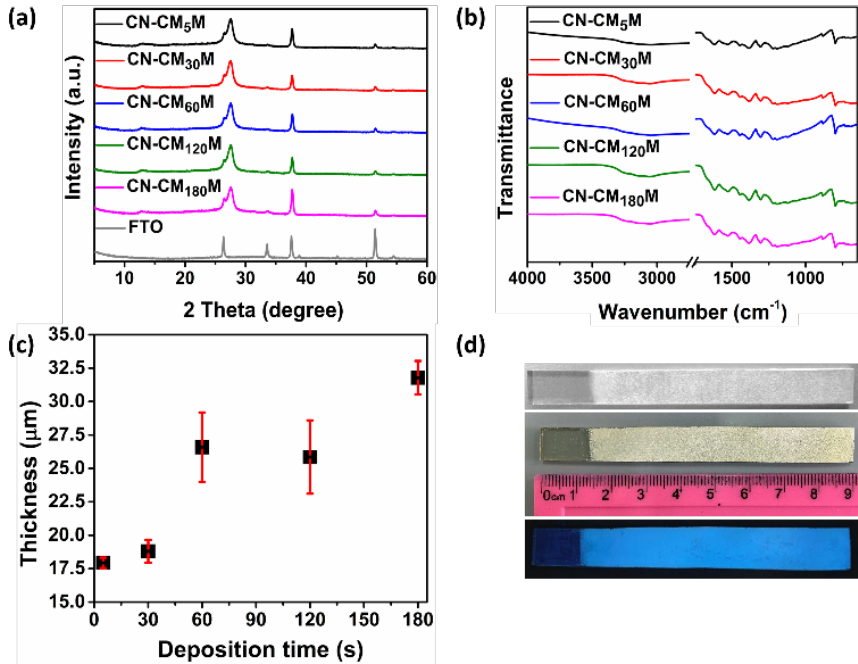

(d)

Wavenumber $\left(\mathrm{cm}^{-1}\right)$

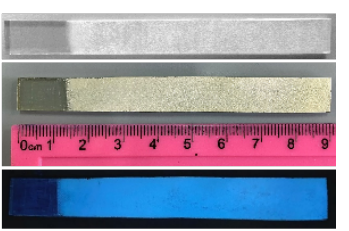

Fig. 3 (a) XRD patterns and (b) FTIR spectra of CN-CMxM electrodes. (c) Film thickness of $\mathrm{CN}-\mathrm{CM}_{x} \mathrm{M}$ electrodes as function of deposition time. (d) Digital photos of $1 \times 9 \mathrm{~cm}^{2}$ electrodes before $\left(\mathrm{CM}_{60}\right.$, white) and after calcination at $550{ }^{\circ} \mathrm{C}$ without $\left(\mathrm{CN}-\mathrm{CM}_{60} \mathrm{M}\right.$, yellow) and under UV ( $365 \mathrm{~nm}$ ) excitation ( $\mathrm{CN}-\mathrm{CM}_{60} \mathrm{M}$, lighted in blue).

The absorption spectra (Fig. 4a) of the $\mathrm{CN}-\mathrm{CM}_{x} \mathrm{M}$ electrodes show almost the same absorption onset $c a .480 \mathrm{~nm}$, which corresponds to a bandgap of about $2.58 \mathrm{eV}$ (calculated using a Tauc plot analysis, Fig. S12). The electrodes formed using 60180 s EPD (i.e., $\mathrm{CN}-\mathrm{CM}_{x} \mathrm{M}, x=60,120,180$ ) presented a higher optical density due to increased film thickness. The photoluminescence (PL) spectra of the $\mathrm{CN}-\mathrm{CM}_{x} \mathrm{M}$ electrodes indicate an emission peak at $\sim 460 \mathrm{~nm}$ with no significant changes between the electrodes (Fig. 4b).

As a proof of concept for the generality of this method (seeding layer together with $\mathrm{CN}$ precursor vapor), a $\mathrm{CN}$ $\mathrm{CM}_{120} \mathrm{CM}$ electrode $\left(\mathrm{CM}_{120}\right.$ electrode calcined together with 1.0 $\mathrm{g}$ of $\mathrm{CM}$ powder) was prepared. SEM images resemble a more porous but less robust and compact film compared to $\mathrm{CN}$ $\mathrm{CM}_{120} \mathrm{M}$ (Fig. S13). The UV-vis absorption curve of $\mathrm{CN}-\mathrm{CM}_{120} \mathrm{CM}$ electrode is slightly blue-shifted compared to $\mathrm{CN}-\mathrm{CM}_{120} \mathrm{M}$ electrode (Fig. S14a), corresponding to a wider band gap of 2.68 $\mathrm{eV}$ compared to $2.56 \mathrm{eV}$ of the electrode prepared with $\mathrm{M}$ powder as the vapor deposition source (Fig. S14b). Photoluminescence spectra of the $\mathrm{CN}-\mathrm{CM}_{120} \mathrm{CM}$ show significant quenching relative to the $\mathrm{CN}-\mathrm{CM}_{120} \mathrm{M}$ (Fig. S14c).

The prepared $\mathrm{CN}-\mathrm{CM}_{x} \mathrm{M}$ electrodes were tested as photoanodes in PEC water-splitting using a standard three electrode setup. ${ }^{11}$ Photocurrent density was measured at 1.23 $V$ vs. reversible hydrogen electrode (RHE) in $0.1 \mathrm{M} \mathrm{KOH}$ in the dark and under one-sun illumination using both front- and backside illumination. Illuminating from the back results in higher photocurrent densities compared to front-side by about $20 \mu \mathrm{A}$ $\mathrm{cm}^{-2}$ for all electrodes. This phenomenon probably stands for a non-optimal layer thickness which leads to a shorter required electron diffusion length in the case of back-illumination (Fig. S15a-e). A comparison between the electrodes under back-side illumination reveals that $\mathrm{CN}-\mathrm{CM}_{60} \mathrm{M}$ and $\mathrm{CN}-\mathrm{CM}_{120} \mathrm{M}$ have the highest photocurrent density of approximately $47 \mu \mathrm{A} \mathrm{cm}^{-2}$ (Fig. $\mathrm{S} 15 \mathrm{f})$. In addition, compared to $\mathrm{CN}-\mathrm{CM}_{120} \mathrm{M}$, the photocurrent density of the $\mathrm{CN}-\mathrm{CM}_{120} \mathrm{CM}$ electrode shows low stability and a 

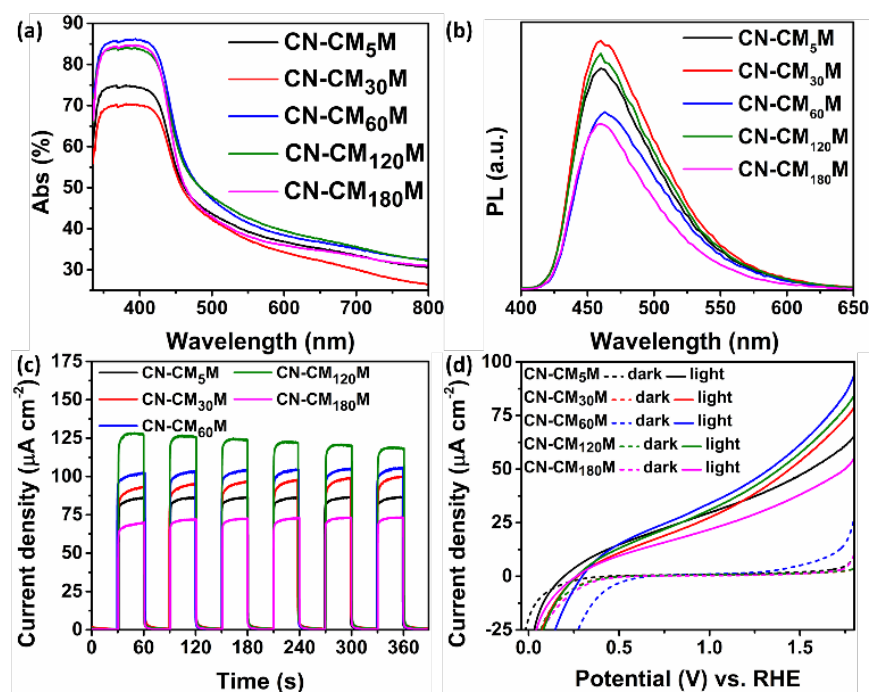

Fig. 4 Optical characterization of $\mathrm{CN}-\mathrm{CM}_{x} \mathrm{M}$ electrodes. (a) UV-vis absorption spectra, an (b) photoluminescence spectra $\left(\lambda_{\mathrm{ex}}=380 \mathrm{~nm}\right)$. (c) Photocurrent densities of $\mathrm{CN}-\mathrm{CM}_{x} \mathrm{M}$ electrodes at $1.23 \mathrm{~V}$ vs. RHE in $0.1 \mathrm{M} \mathrm{KOH}$ aqueous solution containing $10 \% \mathrm{v} / \mathrm{v}$ TEOA hole scavenger upon on/off back-side illumination (1 sun). (d) LSV curves of $\mathrm{CN}-\mathrm{CM}_{\mathbf{x}} \mathrm{M}$ electrode in $0.1 \mathrm{M} \mathrm{KOH}$ aqueous solution in the dark (dashed) and under back-side illumination (1 sun, complete lines).

sharp decay (Fig. S16). We note, that the current performances of $\mathrm{CN}$ electrodes in PEC are still low compared to the state-ofart semiconductors owing to the limited light harvesting and charge separation properties. ${ }^{34-36}$

With the addition of triethanolamine $(10 \% \mathrm{v} / \mathrm{v}$ TEOA in 0.1 $\mathrm{M} \mathrm{KOH}$ ) acting as a hole scavenger, the electrodes showed higher photocurrent densities and certain improvement in the stability (Fig. 4c). $\mathrm{CN}-\mathrm{CM}_{120} \mathrm{M}$ achieved the highest photocurrent density of about $122 \mu \mathrm{A} \mathrm{cm}^{-2}$. As the difference in the thickness between $\mathrm{CN}-\mathrm{CM}_{60} \mathrm{M}$ and $\mathrm{CN}-\mathrm{CM}_{120} \mathrm{M}$ is insignificant ( 26.6 and $25.9 \mu \mathrm{m}$, respectively), the photocurrent densities were relatively similar (122 and $104 \mu \mathrm{A} \mathrm{cm}-2)$. CN$\mathrm{CN}_{180} \mathrm{M}$ showed the lowest photocurrent density, which we ascribe to the thicker film $(31.8 \mu \mathrm{m})$, which hinders the performance, probably due to increased recombination in the bulk and decreased conductivity. Long-term stability tests under the same conditions show that more than $70 \%$ of the initial photocurrent of the $\mathrm{CN}-\mathrm{CM}_{x} \mathrm{M}$ electrodes is preserved after $3 \mathrm{~h}$ of continuous illumination (Fig. S17).

Linear sweep voltammetry (LSV) curves in the dark and under one-sun illumination in $0.1 \mathrm{M} \mathrm{KOH}$ aqueous solutions $(\mathrm{pH}$ $\approx 13$ ) exhibit a typical PEC behavior (Fig. 4d). The obtained low onset potentials reveal that the photocurrent starts $\sim 1 \mathrm{~V}$ below the 'dark' thermodynamic water oxidation potential $(1.23 \mathrm{~V} v$ s. RHE).

Mott-Schottky analysis (Fig. S18) for $\mathrm{CN}_{-} \mathrm{CM}_{x} \mathrm{M}$ and $\mathrm{CN}$ $\mathrm{CM}_{120} \mathrm{CM}$ electrodes indicates an $\mathrm{n}$-type semiconductor behavior. The flat band (FB) potentials of the electrodes were estimated from the extrapolated linear fits that intercept the $x$ axis (potential (V) vs. RHE). The full band position diagrams determined from the optical analysis and the Mott-Schottky measurements (Fig. S19) reveal that all the electrodes are suitable for water reduction and oxidation.
The incident photon-to-current conversion efficiency (IPCE) measurement at $1.23 \mathrm{~V}$ vs. RHE of the $\mathrm{CN}-\mathrm{CM}_{120} \mathrm{M}$ electrode with and without the addition of hole scavenger at different wavelengths has revealed that the photoresponse onset is expanded into the visible region, up to $450 \mathrm{~nm}$, as the $480 \mathrm{~nm}$ shows a negligible photoresponse (Fig. S20) owing to the direct band gap of $\mathrm{CN}$ materials. The maximum efficiency with $10 \%$ $(\mathrm{v} / \mathrm{v})$ TEOA was calculated to be $1.8 \%$ at $400 \mathrm{~nm}$ compared to $1.1 \%$ without.

The $\mathrm{H}_{2}$ generation in the presence of TEOA in $0.1 \mathrm{M} \mathrm{KOH}$ solution was tracked using gas chromatography (GC) (see Fig. $\mathrm{S} 21$ ). The $\mathrm{CN}-\mathrm{CM}_{120} \mathrm{M}$ photoanode achieved a $\mathrm{H}_{2}$ generation rate of $0.55 \mathrm{mmol} \mathrm{g}^{-1} \mathrm{~h}^{-1}$. The overall Faraday efficiency (FE) for $\mathrm{CN}-\mathrm{CM}_{120} \mathrm{M}$ at $3 \mathrm{~h}$ is $74.9 \%$.

\section{Conclusions}

To conclude, we demonstrated a facile and scalable growth technique of carbon nitride films using a supramolecular complex composed of $\mathrm{CN}$ monomers as a seeding layer on FTO followed by the controlled growth of $\mathrm{CN}$ by vapor deposition means. The successful seeding layer deposition was achieved by using electrophoretic deposition of supramolecular complexes, resulting in good control over the layer thickness and composition. The use of seeding layers for the $\mathrm{CN}$ growth enables good adhesion to the substrate and improved photoelectrochemical properties as well as unique electronic structure.

\section{Conflicts of interest}

There are no conflicts to declare.

\section{Acknowledgements}

We thank the scientific staff of the Ilse Katz Institute for Nanoscale Science and Technology for help with material characterization and Mr. Jesús Barrio for fruitful discussion. We acknowledge the financial support of the Israel Science Foundation (ISF), grant No. 1161/17 and the Minerva Center No. 117873. This project has received funding from the European Research Council (ERC) under the European Union's Horizon 2020 research and innovation programme (grant agreement No. [849068]).

\section{References}

1. Y. Zheng, J. Liu, J. Liang, M. Jaroniec and S. Z. Qiao, Energy Environ. Sci., 2012, 5, 6717-6731.

2. Y. Wang, X. Wang and M. Antonietti, Angew. Chem. Int. Ed., 2012, 51, 68-89.

3. A. Savateev, I. Ghosh, B. König and M. Antonietti, Angewandte Chemie International Edition, 2018, 57, 15936-15947. 
4. F. K. Kessler, Y. Zheng, D. Schwarz, C. Merschjann, W. Schnick, X. Wang and M. J. Bojdys, Nature Reviews Materials, 2017, 2, 17030.

5. S. Cao, J. Low, J. Yu and M. Jaroniec, Adv. Mater., 2015, 27, 2150-2176.

6. W. J. Ong, L. L. Tan, Y. H. Ng, S. T. Yong and S. P. Chai, Chem Rev, 2016, 116, 7159-7329.

7. Y. Zheng, L. Lin, B. Wang and X. Wang, Angew. Chem. Int. Ed., 2015, 54, 12868-12884.

8. Z. Zhou, Y. Zhang, Y. Shen, S. Liu and Y. Zhang, Chemical Society Reviews, 2018, 47, 2298-2321.

9. J. Safaei, N. A. Mohamed, M. F. Mohamad Noh, M. F. Soh, N. A. Ludin, M. A. Ibrahim, W. N. Roslam Wan Isahak and M. A. Mat Teridi, Journal of Materials Chemistry A, 2018, 6, 22346-22380.

10. Q. Ruan, M. K. Bayazit, V. Kiran, J. Xie, Y. Wang and J. Tang, Chemical Communications, 2019, 55, 7191-7194.

11. M. Volokh, G. Peng, J. Barrio and M. Shalom, Angew. Chem. Int. Ed., 2019, 58, 6138-6151.

12. J. Xu, T. J. K. Brenner, L. Chabanne, D. Neher, M. Antonietti and M. Shalom, J. Am. Chem. Soc., 2014, 136, 13486-13489.

13. Q. Ruan, W. Luo, J. Xie, Y. Wang, X. Liu, Z. Bai, C. J. Carmalt and J. Tang, Angew. Chem. Int. Ed., 2017, 56, 8221-8225.

14. J. Bian, Q. Li, C. Huang, J. Li, Y. Guo, M. Zaw and R.-Q. Zhang, Nano Energy, 2015, 15, 353-361.

15. K. Wu and I. Zhitomirsky, International Journal of Applied Ceramic Technology, 2011, 8, 920-927.

16. L. Besra and M. Liu, Prog. Mater Sci., 2007, 52, 1-61.

17. A. R. Boccaccini, J. Cho, J. A. Roether, B. J. C. Thomas, E. Jane Minay and M. S. P. Shaffer, Carbon, 2006, 44, 31493160.

18. Z.-S. Wu, S. Pei, W. Ren, D. Tang, L. Gao, B. Liu, F. Li, C. Liu and H.-M. Cheng, Adv. Mater., 2009, 21, 1756-1760.

19. M. Fayette, A. Nelson and R. D. Robinson, J. Mater. Chem. A, 2015, 3, 4274-4283.

20. J. Liu, Z. Wu, T. Li, D. Zhou, K. Zhang, Y. Sheng, J. Cui, H. Zhang and B. Yang, Nanoscale, 2016, 8, 395-402.

21. A. Salant, M. Shalom, I. Hod, A. Faust, A. Zaban and U. Banin, ACS Nano, 2010, 4, 5962-5968.

22. A. Vázquez, I. A. López and I. Gómez, Journal of Materials Science, 2013, 48, 2701-2704.

23. S. L. Allen and F. P. Zamborini, Langmuir : the ACS journal of surfaces and colloids, 2019, 35, 2137-2145.

24. I. Hod, W. Bury, D. M. Karlin, P. Deria, C.-W. Kung, M. J. Katz, M. So, B. Klahr, D. Jin, Y.-W. Chung, T. W. Odom, O. K. Farha and J. T. Hupp, Adv. Mater., 2014, 26, 6295-6300. I. Liberman, W. He, R. Shimoni, R. Ifraemov and I. Hod, Chemical Science, 2020, 11, 180-185.

26. M. Volokh, M. Diab, K. Flomin and T. Mokari, J. Colloid Interface Sci., 2018, 515, 221-231.

27. J. Xu and M. Shalom, ACS Appl Mater Interfaces, 2016, 8, 13058-13063.

28. J. Barrio and M. Shalom, ChemCatChem, 2018, 10, 5573 5586.

29. M. Shalom, M. Guttentag, C. Fettkenhauer, S. Inal, D. Neher, A. Llobet and M. Antonietti, Chemistry of Materials, 2014, 26, 5812-5818.

30. S. Dolai, J. Barrio, G. Peng, A. Grafmüller and M. Shalom, Nanoscale, 2019, 11, 5564-5570.

31. Y.-S. Jun, E. Z. Lee, X. Wang, W. H. Hong, G. D. Stucky and A. Thomas, Adv. Funct. Mater., 2013, 23, 3661-3667.
32. J. Barrio, L. Lin, X. Wang and M. Shalom, ACS Sustainable Chemistry \& Engineering, 2018, 6, 519-530.

33. W. Xiong, F. Huang and R.-Q. Zhang, Sustainable Energy \& Fuels, 2020, 4, 485-503.

34. Y. Fang, X. Li and X. Wang, ACS Catalysis, 2018, 8, 87748780.

35. Y. Fang, X. Li and X. Wang, ChemSusChem, 2019, 12, 26052608.

36. Y. Fang, X. Li, Y. Wang, C. Giordano and X. Wang, Appl. Catal., B, 2020, 268, 118398. 
Electronic Supplementary Material (ESI) for Sustainable Energy \& Fuels.

This journal is () The Royal Society of Chemistry 2020

\section{Electronic Supplementary Information}

Electrophoretic deposition of supramolecular complexes for the formation of carbon nitride films

Liel Abisdris ${ }^{a}$, Jonathan Tzadikov ${ }^{a}$, Neeta Karjule ${ }^{a}$, Adi Azoulay ${ }^{a}$, Michael Volokha, Menny Shalom $^{* a}$

a. Department of Chemistry and Ilse Katz Institute for Nanoscale Science and Technology, Ben-Gurion University of the Negev, Beer-Sheva 8410501, Israel.

*E-mail: mennysh@bgu.ac.il 


\section{Experimental}

\section{$\underline{\text { Materials }}$}

All reagents and solvents (abbreviation, purity, manufacturer) were used as received: cyanuric acid (CA, 98\%, Merck), melamine (M, 99\%, Sigma-Aldrich), toluene (AR, LOBA Chemie), potassium hydroxide pellets ( $\mathrm{KOH}, \mathrm{AR}, 85 \%$, LOBA Chemie), sodium sulphate anhydrous $\left(\mathrm{Na}_{2} \mathrm{SO}_{4}, \mathrm{AR}, 99 \%\right.$, Loba Chemie), and triethanolamine (TEOA, $\geq$ 99.0\%, Glentham Life Sciences). Deionized water $\left(18.2 \mathrm{M} \Omega \mathrm{cm}\right.$ resistivity at $25{ }^{\circ} \mathrm{C}$, purified using a Merck Millipore Direct-Q3 system) was used for all aqueous solutions. Fluorine-doped tin oxide coated glass (FTO, 12-14 $\Omega \mathrm{sq}^{-1}$, Xop Glass company - Spain) was cut, washed with an aqueous detergent solution (1\% w/v Alconox), and sonicated for 20 min with acetone (AR, Bio-Lab) and ethanol (AR, Macron Fine Chemicals), subsequently.

\section{Supramolecular precursor synthesis}

A cyanuric acid-melamine $(\mathrm{CM})$ supramolecular complex was prepared by mixing equal amounts of $\mathrm{CA}$ and $\mathrm{M}(4 \mathrm{mmol})$ in $30 \mathrm{~mL}$ water. The mixture was shaken for $2 \mathrm{~h}$, centrifuged and dried for $24 \mathrm{~h}$ at $60{ }^{\circ} \mathrm{C}$ in a vacuum oven, resulting in a CM powder.

\section{Supramolecular-films preparation}

CM powder was ground for 45 min using Fritsch Pulverisette 7 planetary ball mill (3 mm $\mathrm{ZrO}_{2}$ balls, dry milling), washed with water, centrifuged, and dried for 24 hours at $60{ }^{\circ} \mathrm{C}$ in a vacuum oven. Next, $50 \mathrm{mg}$ of ball-milled CM powder was dispersed in $5 \mathrm{~mL}$ of toluene to form a stable colloidal suspension $\left(10 \mathrm{mg} \mathrm{mL}^{-1}\right)$. The obtained suspension was used as the deposition medium for forming CM films on top of FTO by electrophoretic deposition (EPD). The EPD setup consisted of two FTOs dipped into the deposition medium in a parallel capacitor configuration, i.e., the FTO electrodes in the suspension were connected to a DC voltage using an ENDURO power supply. A constant voltage of $300 \mathrm{~V}$ was applied during the deposition for $2 \mathrm{~s}, 5 \mathrm{~s}, 15 \mathrm{~s}, 30 \mathrm{~s}, 45 \mathrm{~s}, 60 \mathrm{~s}, 120 \mathrm{~s}$, and $180 \mathrm{~s}$.

\section{CN-films formation}


Each $\mathrm{CM}_{x}(x=2,5,15,30,45,60,120$, and $180 \mathrm{~s})$ electrode was placed in a glass tube (16 $\mathrm{mm}$ diameter $\times 100 \mathrm{~mm}$ length) along with $1.0 \mathrm{~g}$ melamine as a $\mathrm{CN}$ precursor powder for the vapor deposition. The tube was purged with $\mathrm{N}_{2}$ for several seconds and covered tightly with an $\mathrm{Al}$ foil. The electrodes in each tube were calcined under $\mathrm{N}_{2}$ atmosphere (constant flow rate of $120 \mathrm{~mL} \mathrm{~min}^{-1}$ ), to $550{ }^{\circ} \mathrm{C}$ with a heating ramp of $5{ }^{\circ} \mathrm{C} \mathrm{min}^{-1}$ and kept for $4 \mathrm{~h}$, resulting in $\mathrm{CN}-\mathrm{CM}_{x} \mathrm{M}$ electrodes. In the same calcination conditions, $\mathrm{CM}_{120}$ electrode with $\mathrm{CM}$ powder $(1.0 \mathrm{~g})$, which was used as a $\mathrm{CN}$ precursor powder instead of melamine, was prepared, forming $\mathrm{CN}-\mathrm{CM}_{120} \mathrm{CM}$ electrode, and $\mathrm{CM}_{60}$ electrodes with different amounts of melamine powder were prepared, forming $\mathrm{CN}-\mathrm{CM}_{60} \mathrm{M}_{y}$ electrodes $(y=0.2,0.4$, 0.6 and $0.8 \mathrm{~g}$ ).

\section{Characterization}

FTIR spectra were obtained by using a Thermo Scientific Nicolet iS5 in the $650-4000 \mathrm{~cm}^{-1}$ range using a diamond iD7 ATR. UV-vis spectra were acquired using a Cary 100 spectrophotometer equipped with a DRA (integrating sphere), in transmittance $(T)$ and reflectance $(R)$ modes, while the $A b s(\%)$ has calculated according to $100 \%-T(\%)-R(\%)$. Photoluminescence spectra were measured by using Edinburgh instruments FLS920P Fluorimeter with an excitation wavelength of $\lambda_{\mathrm{ex}}=380 \mathrm{~nm}$. Digital photos under UV (365 nm) illumination were taken using a TLC viewing cabinet Vilber-Lourmat CN-6. X-ray diffraction patterns (XRD) were recorded on a PANalytical's Empyrean Diffractometer equipped with a position sensitive detector $\mathrm{X}^{\prime}$ Celerator. The data was collected for $2 \theta$ ranging from $5^{\circ}$ to $60^{\circ}$, with a scanning time of $\sim 7$ min using $\mathrm{Cu} \mathrm{K} \alpha$ radiation $(\lambda=1.54178 \AA, 40 \mathrm{kV}, 30 \mathrm{~mA})$. XPS data was collected by using an X-ray photoelectron spectrometer (Thermo Fisher ESCALAB 250) ultrahigh vacuum $\left(1 \times 10^{-9}\right.$ bar $)$ with an $\mathrm{A} 1 \mathrm{~K} \alpha \mathrm{X}$-ray source and a monochromator. The X-ray beam size was $500 \mu \mathrm{m}$ and survey spectra was recorded with a pass energy (PE) of $150 \mathrm{eV}$ and high energy resolution spectra were recorded with a PE of $20 \mathrm{eV}$. All XPS spectra peaks were shifted relative to the $\mathrm{C} 1 \mathrm{~s}$ peak, positioned at $284.8 \mathrm{eV}$, to correct for charging effects. The XPS results were analyzed by using the AVANTGE software. For measuring film thickness, the electrodes were scratched in three different areas on top of the same film, using a needle (1.20 mm diameter). Thickness profile was obtained by using a 3D laser microscope (LEXT OLS5000), under low magnification $(\times 10)$, via focusing on a specific scan area around the scratches. The roughness from both sides of the scratch (300 
$\times 200 \mu \mathrm{m}$ ) was averaged by the software, then the distance between the lowest part (FTO level), to the averaged top part of the coating (to the left and right of the scratch) has been calculated. Scanning electron microscopy (SEM) images were recorded on an FEI Verios 460L high resolution SEM, operated at $3.0 \mathrm{kV}$, and equipped with a FEG source. To avoid charging effects, the samples were coated with $10 \mathrm{~nm}$ of sputtered gold (for $\mathrm{CN}$ precursors) or a carbon (for $\mathrm{CN})$.

\section{Photoelectrochemical measurements}

Photoelectrochemical analysis was performed using a three-electrode system coupled to PalmSens3 (chronoamperometry, linear sweep voltammetry) or Metrohm Autolab (MottSchotkky and IPCE) potentiostats. A Pt-plate $\left(1.0 \mathrm{~cm}^{2}\right)$, and an $\mathrm{Ag} / \mathrm{AgCl}$ (saturated $\mathrm{KCl}$ ) electrodes were used as counter and reference electrodes, respectively. The electrolyte was either a $0.1 \mathrm{M} \mathrm{KOH}$ aqueous solution $(\mathrm{pH} \approx 13)$ or a $0.1 \mathrm{M} \mathrm{KOH}$ solution containing $10 \%$ v/v TEOA as a hole scavenger. All the potentials vs. $\mathrm{Ag} / \mathrm{AgCl}$ were converted with respect to a reversible hydrogen electrode (RHE), using the Nernst equation at room temperature:

$E_{R H E}(V)=E_{A g / A g C l}(V)+0.197+0.059 \times p H$

Chronoamperometry measurements were carried out at a bias potential of $1.23 \mathrm{~V} v s$. RHE under one-sun illumination (power density of $100 \mathrm{~mW} \mathrm{~cm}^{-2}$ ), provided by a solar simulator (Newport, OPS-A500, $300 \mathrm{~W}$ Xe arc lamp, equipped with an air mass AM 1.5G and water filters) and calibrated using a power meter (Newport, 919P thermopile detector). The electrolyte was purged with $\mathrm{N}_{2}$ for $15 \mathrm{~min}$, followed by linear sweep voltammetry (LSV) measurements in the dark and under 1 sun illumination, at a scan rate of $10 \mathrm{mV} \mathrm{s}^{-1}$. Mott-Schottky measurements were performed in $1 \mathrm{M} \mathrm{Na}_{2} \mathrm{SO}_{4}$ at a $1.0 \mathrm{kHz}$ frequency. Incident photon-to-current conversion efficiency (IPCE) values at different wavelengths were calculated from the following equation:

$\operatorname{IPCE}(\%)=\frac{J_{K O H-o r-T E O A}\left(A \mathrm{~cm}^{-2}\right) \times 1240}{\lambda(\mathrm{nm}) \times I\left(\mathrm{~W} \mathrm{~cm}^{-2}\right)} \times 100 \%$

Where $J$ is the photocurrent density $\left(J_{\mathrm{KOH}}\right.$ is the photocurrent obtained in $0.1 \mathrm{M} \mathrm{KOH}$ aqueous solution, while $J_{\mathrm{TEOA}}$ is the photocurrent obtained in $0.1 \mathrm{M} \mathrm{KOH}$ aqueous solution 
containing $10 \%(\mathrm{v} / \mathrm{v})$ TEOA; $\lambda$ is the wavelength of the incident monochromatic light (400, 420,450 , and $480 \mathrm{~nm}$ ); $I$ is the light power density. Incident monochromatic light of different wavelengths was obtained by inserting a corresponding band-pass filter (Newport 10BBPF10-400, 10BBPF10-420, 10BBPF10-450, and 10BBPF10-480) between the solar simulator and the PEC cell.

The amount of photogenerated $\mathrm{H}_{2}$ in the reactor headspace was analyzed using a gas chromatograph (Agilent $7820 \mathrm{GC}$ system) equipped with a thermal conductivity detector (TCD).

Faraday efficiency (FE) was calculated using the following equation:

$F E(\%)=\frac{m \cdot n \cdot F}{I \cdot t} \times 100 \%$

Where $m$ is the number of moles of gas actually produced; $n$ is the number of electrons in the electrochemical reaction; $F$ is the Faraday constant; $I$ is photocurrent; $t$ is reaction time. This equation represents the ratio between the actual hydrogen gas evolution rate and calculated one from measuring the generated photocurrent. 

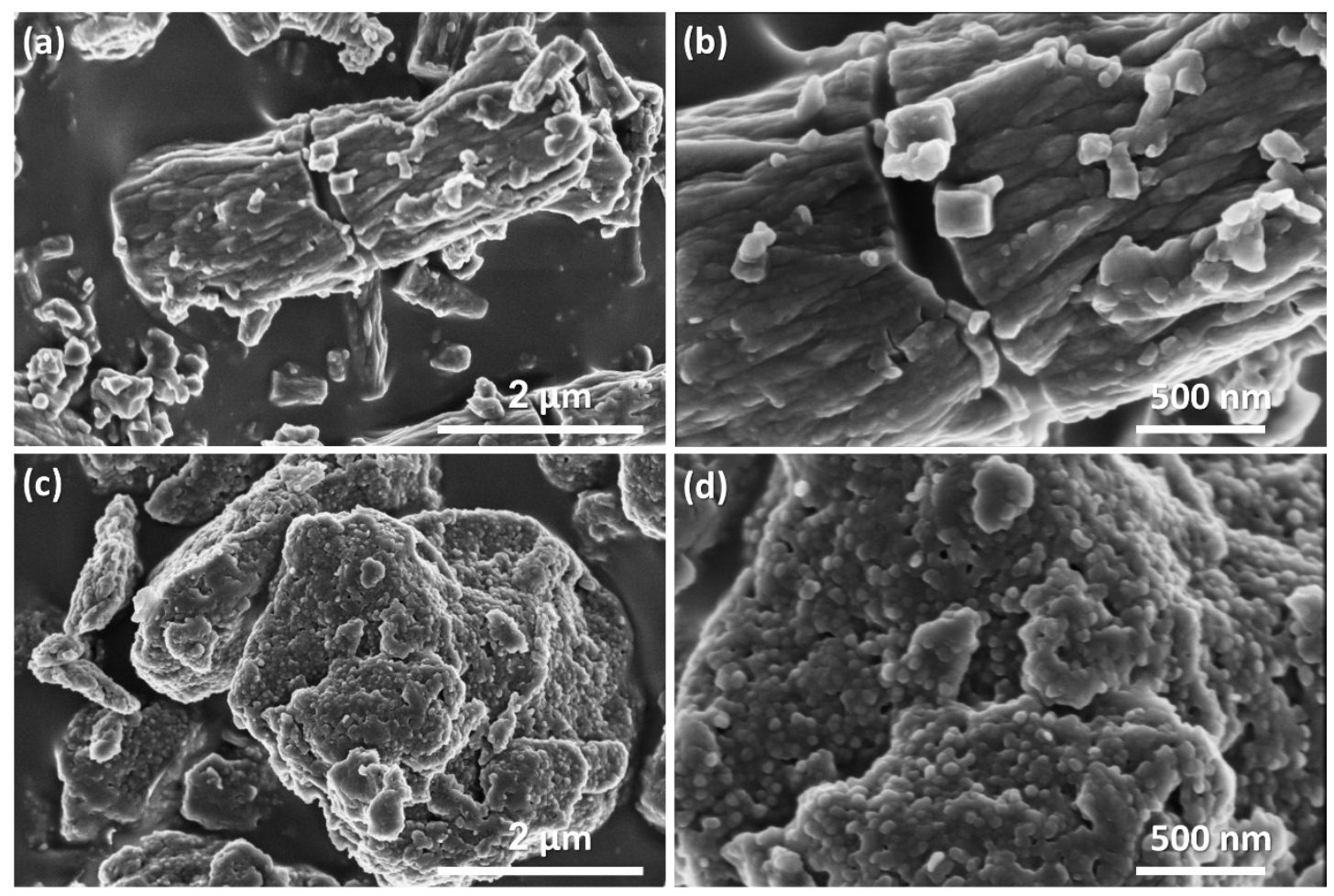

Fig. S1 SEM images of CM powder assembled in water (a)-(b) before and (c)-(d) after ballmilling.
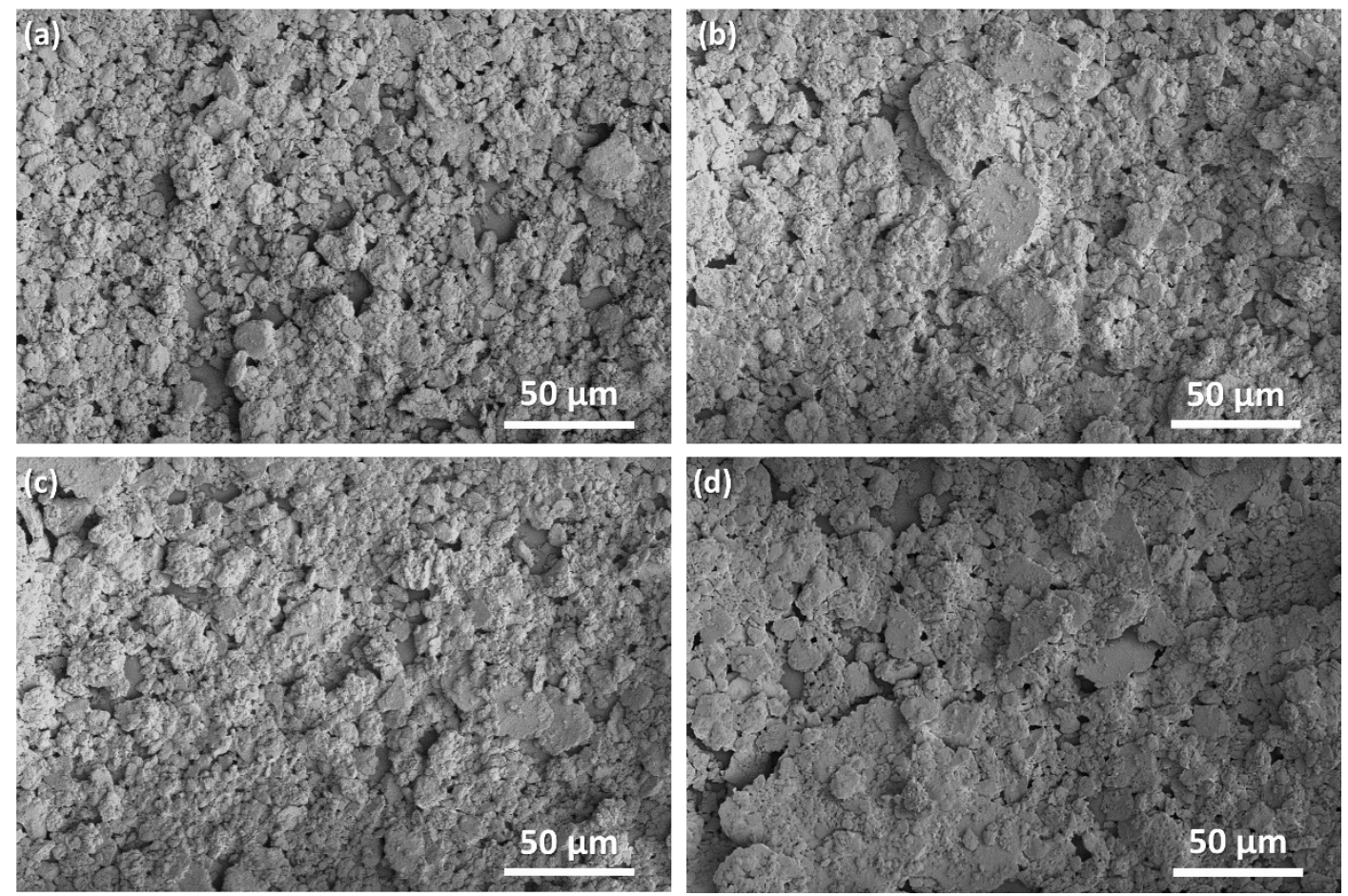

Fig. S2 Top-view SEM images of (a) $\mathrm{CM}_{5}$, (b) $\mathrm{CM}_{30}$, (c) $\mathrm{CM}_{60}$, and (d) $\mathrm{CM}_{180}$ electrodes. 


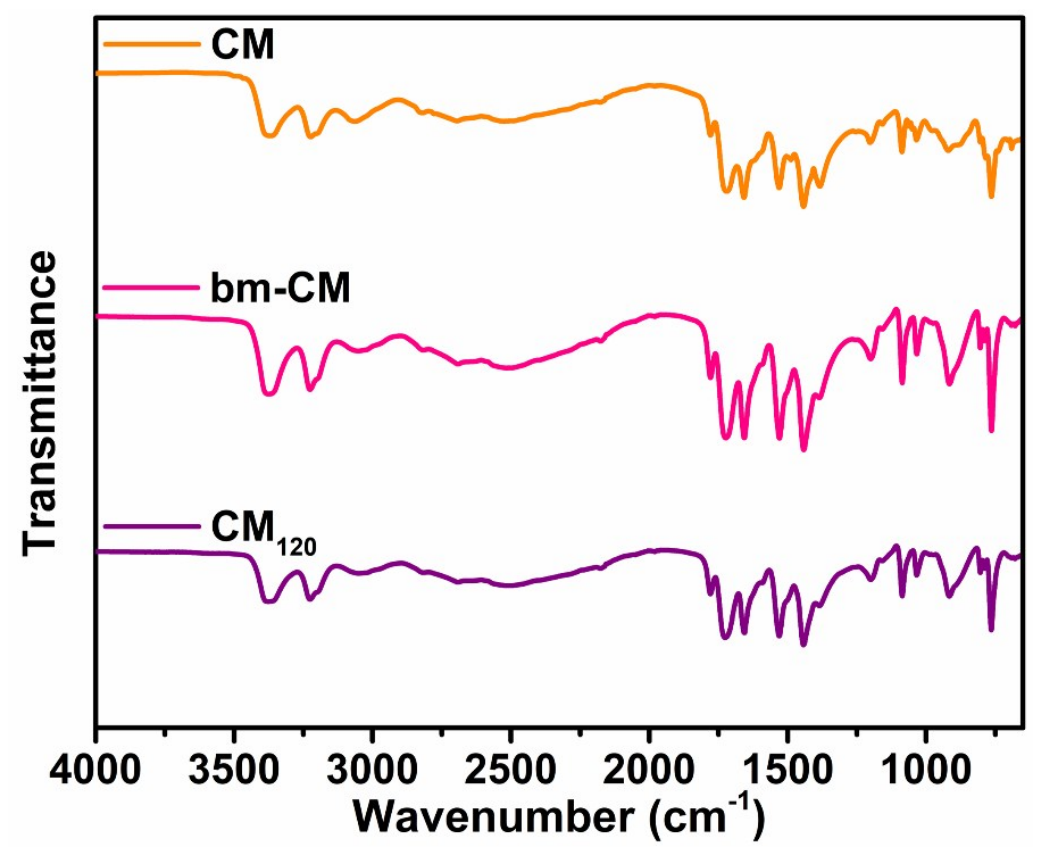

Fig. S3 FTIR spectra of CM powders (assembled in water) before (orange) and after (rose) ball milling, and $\mathrm{CM}_{120}$ electrode (purple). Spectra are offset for clarity.
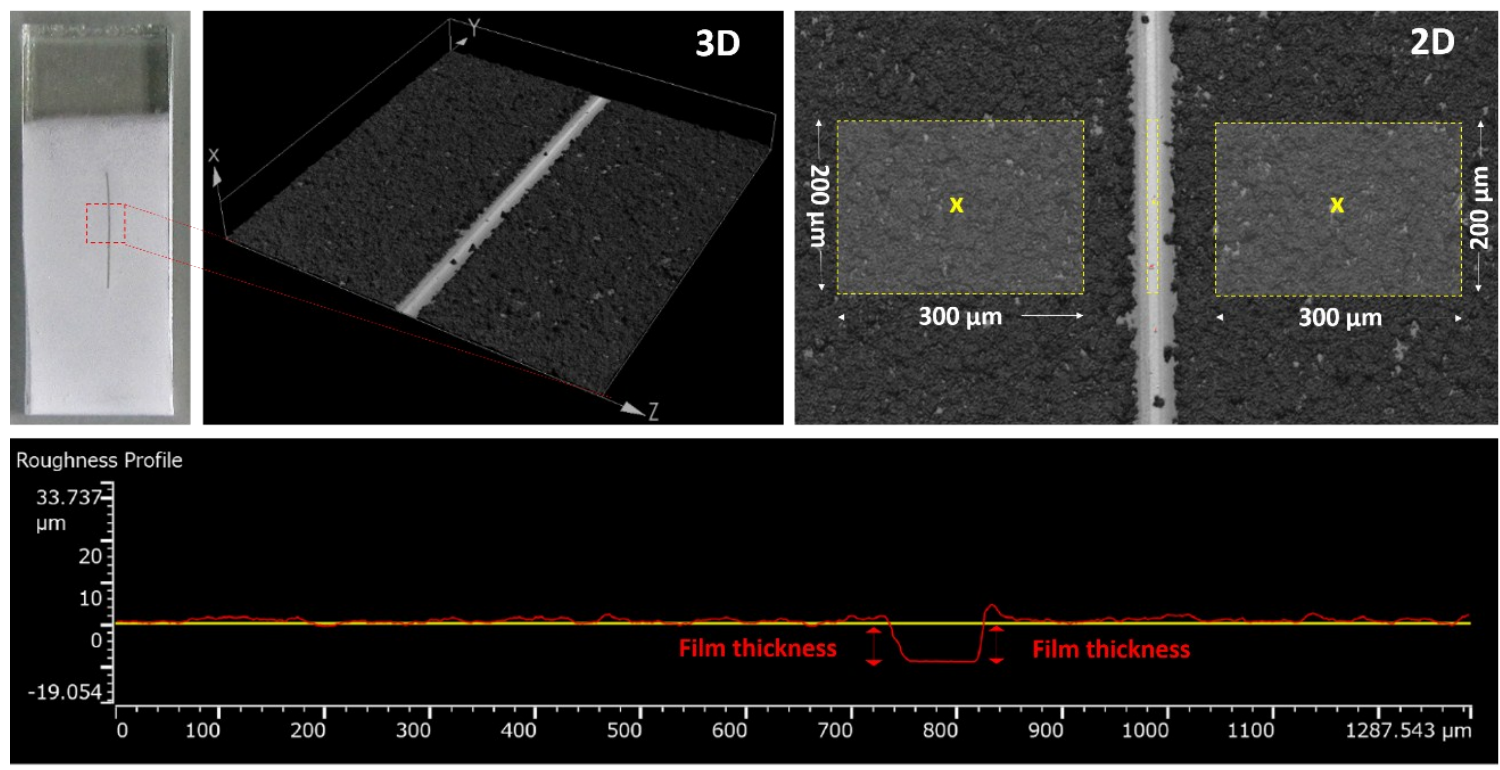

Fig. S4 General thickness profile of a $\mathrm{CM}_{x}$ electrode measured using a 3D laser microscope. 


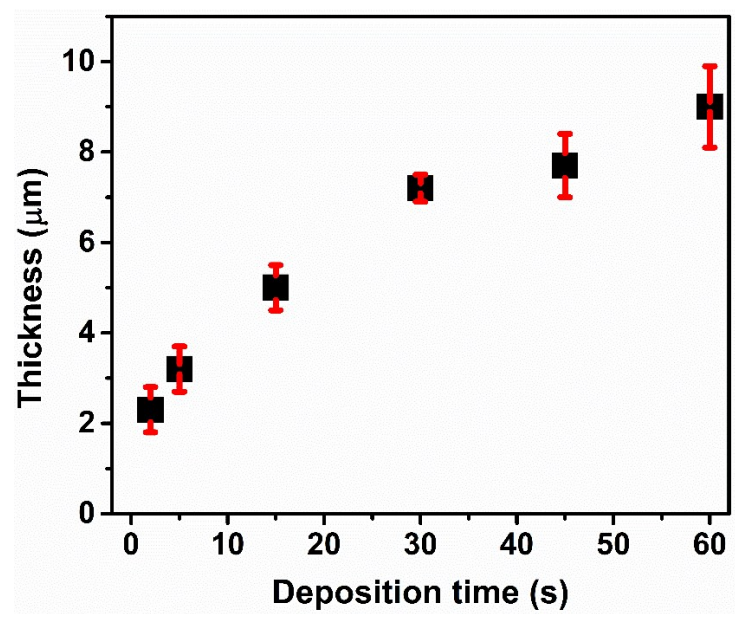

Fig. S5 Film thickness of the $\mathrm{CM}_{x}$ electrodes in EPD time intervals shorter than $60 \mathrm{~s}$ (i.e., $x=2$, $5,15,30,45,60)$ as function of deposition time.

Table S1. Statistical calculations of $\mathrm{CM}_{x}$ films thickness.

\begin{tabular}{|c|c|c|c|}
\hline Deposition time (s) & $\begin{array}{l}\text { Average thickness of both } \\
\text { sides }(\mu \mathrm{m})\end{array}$ & $\begin{array}{l}\text { Total average } \\
\text { thickness }(\mu \mathrm{m})\end{array}$ & Standard deviation $(\mu \mathrm{m})$ \\
\hline \multirow{4}{*}{2} & 1.9 & & \\
\hline & 2.8 & 2.3 & 0.5 \\
\hline & 2.1 & & \\
\hline & 3.6 & & \\
\hline \multirow[t]{3}{*}{5} & 2.6 & 3.2 & 0.5 \\
\hline & 3.3 & & \\
\hline & 4.6 & & \\
\hline \multirow[t]{3}{*}{15} & 5.5 & 5.0 & 0.5 \\
\hline & 4.9 & & \\
\hline & 7.5 & & \\
\hline \multirow[t]{3}{*}{30} & 7.1 & 7.2 & 0.3 \\
\hline & 7.0 & & \\
\hline & 8.1 & & \\
\hline \multirow[t]{3}{*}{45} & 8.1 & 7.7 & 0.7 \\
\hline & 6.9 & & \\
\hline & 9.8 & & \\
\hline \multirow[t]{3}{*}{60} & 8.1 & 9.0 & 0.9 \\
\hline & 9.3 & & \\
\hline & 7.6 & & \\
\hline \multirow[t]{3}{*}{120} & 8.3 & 8.2 & 0.6 \\
\hline & 8.8 & & \\
\hline & 10.1 & & \\
\hline \multirow[t]{2}{*}{180} & 9.0 & 8.6 & 1.7 \\
\hline & 6.8 & & \\
\hline
\end{tabular}



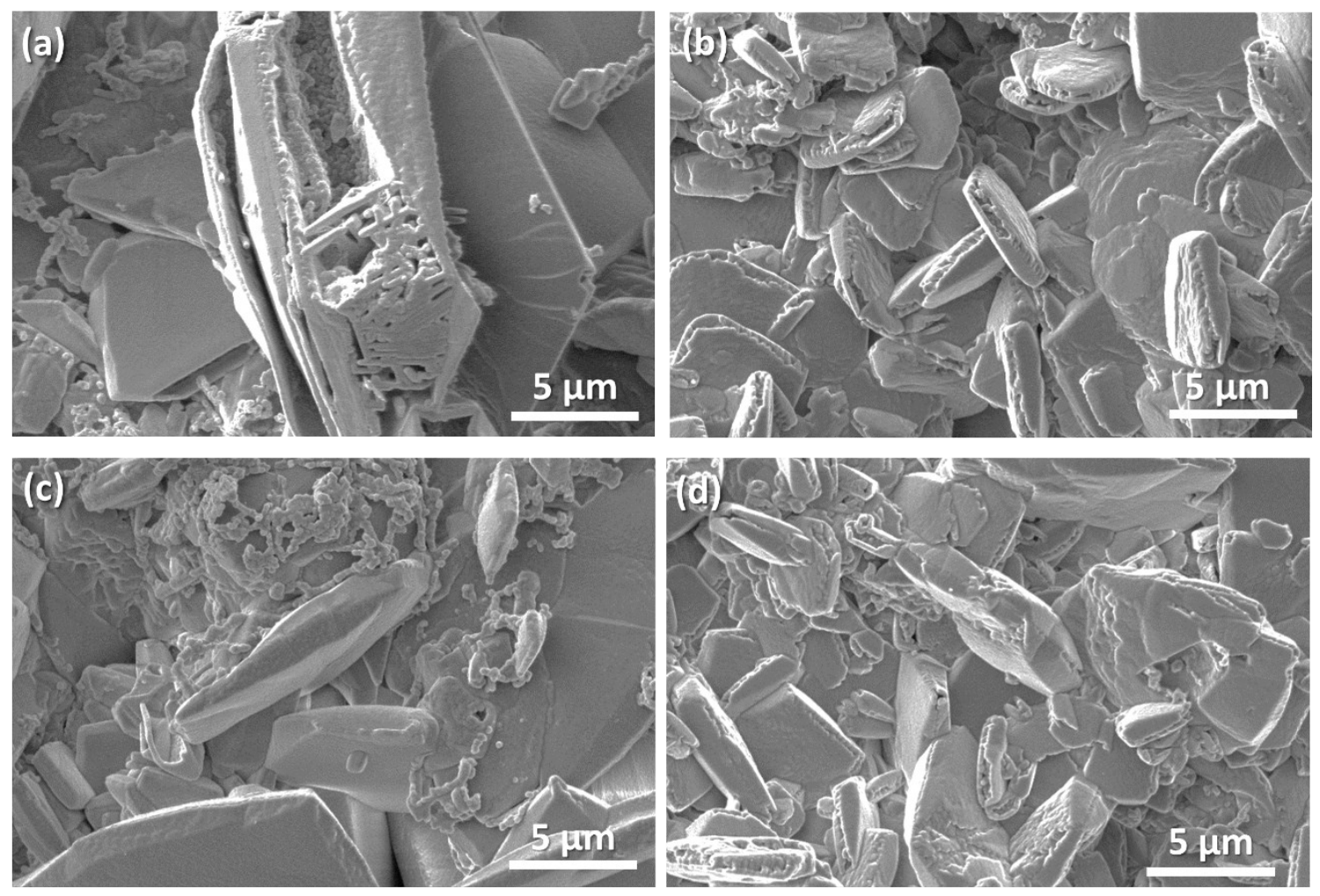

Fig. S6 Top-view SEM images of (a) $\mathrm{CN}_{-} \mathrm{CM}_{5} \mathrm{M}$, (b) $\mathrm{CN}-\mathrm{CM}_{30} \mathrm{M}$, (c) $\mathrm{CN}-\mathrm{CM}_{60} \mathrm{M}$, and (d) $\mathrm{CN}-$ $\mathrm{CM}_{180} \mathrm{M}$ electrodes.
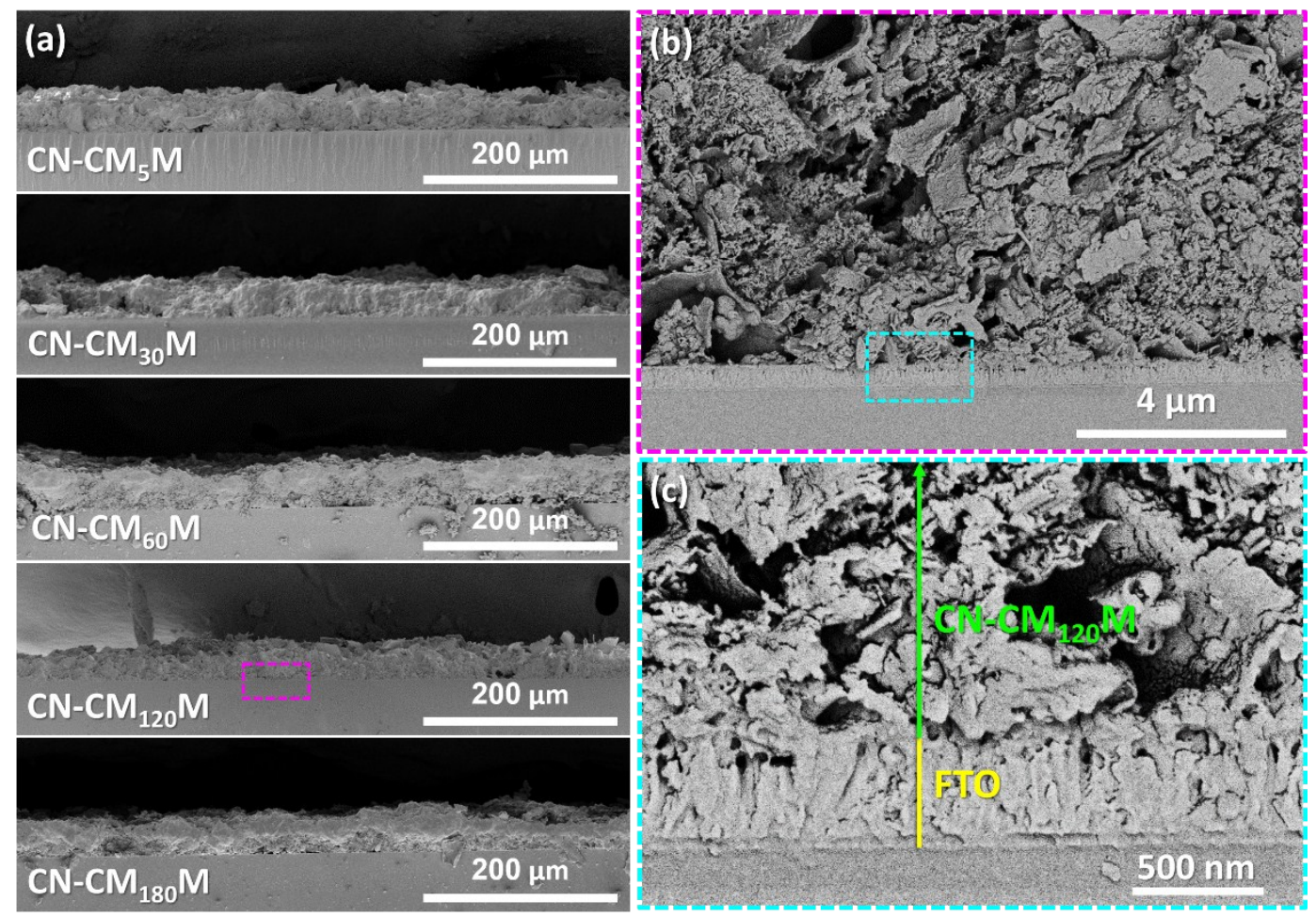

Fig. S7 Cross-sectional SEM images of (a) $\mathrm{CN}-\mathrm{CM}_{x} \mathrm{M}$ electrodes, and (b-c) $\mathrm{CN}-\mathrm{CM}_{120} \mathrm{M}$. 

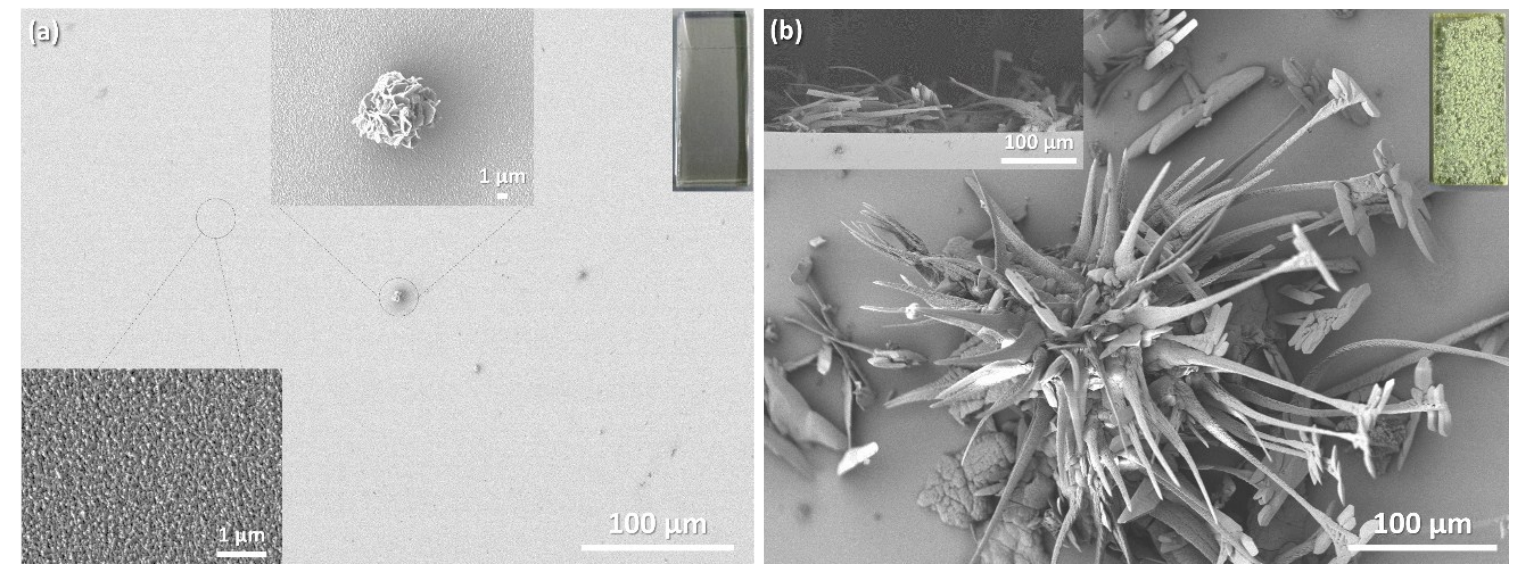

Fig. S8 Top-view SEM images of (a) $\mathrm{CN}-\mathrm{CM}_{60}$ (insets: the corresponding digital photo and topview SEM images), and (b) CN-M (insets: the corresponding digital photo and cross-sectional SEM image) electrodes.
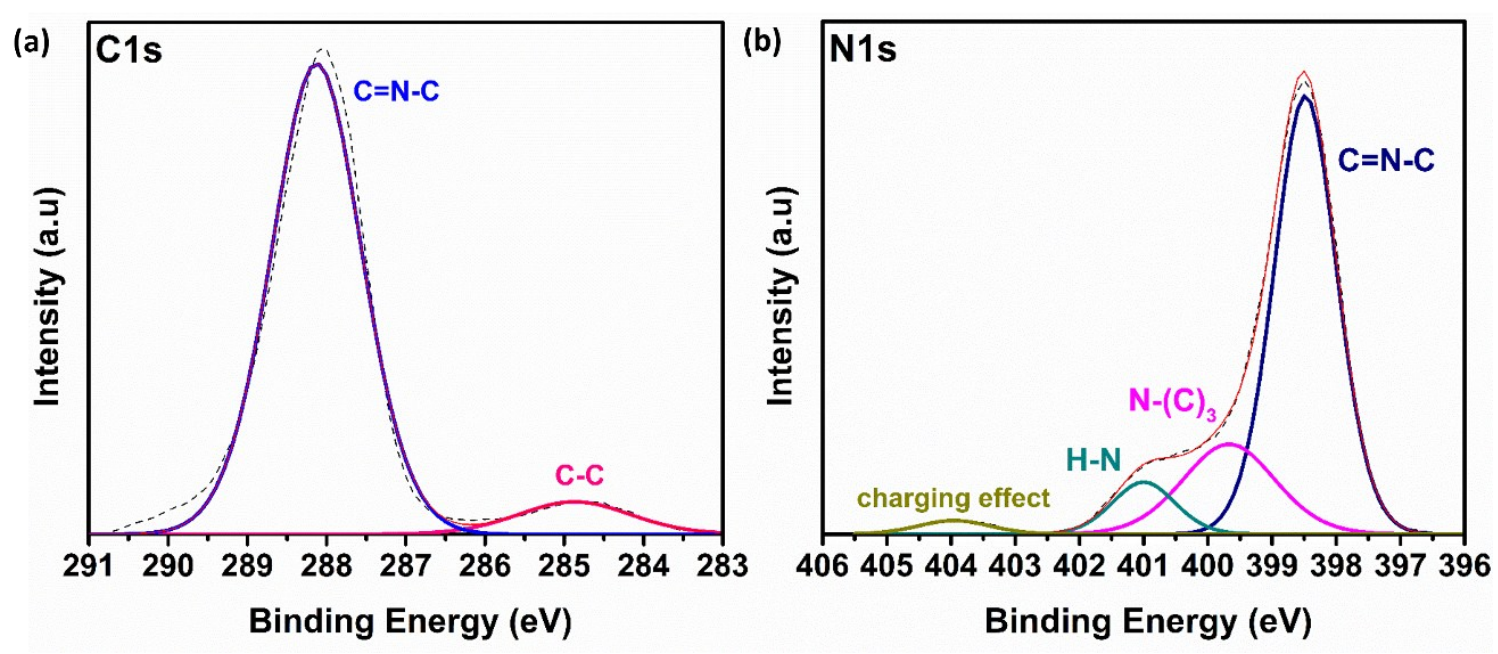

Fig. S9 XPS analysis of CN-CM ${ }_{120} \mathrm{M}$ electrode for (a) C1s, and (b) N1s. 


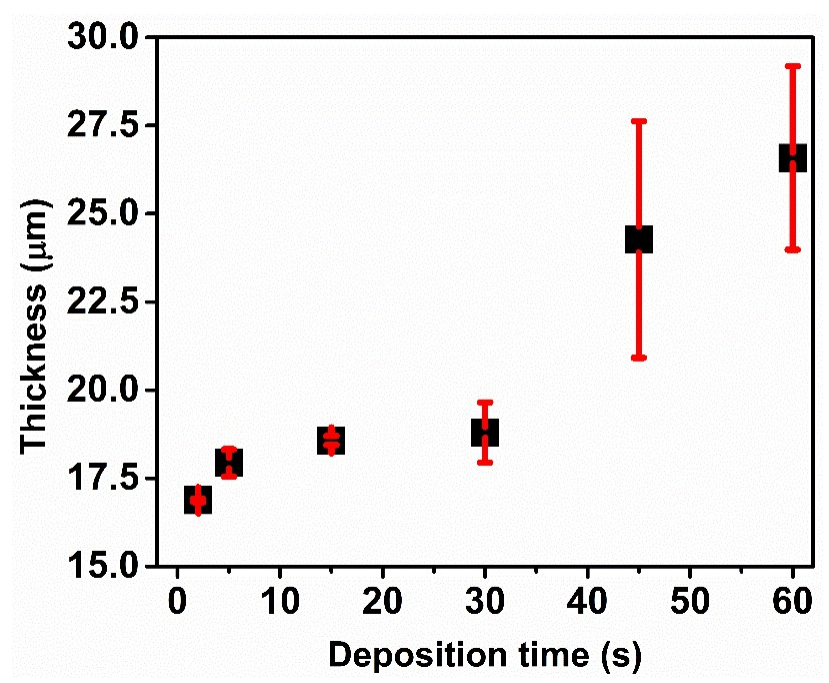

Fig. S10 Final film thickness of the $\mathrm{CN}-\mathrm{CM}_{x} \mathrm{M}$ electrodes (after calcination), which were prepared using EPD time intervals shorter than $60 \mathrm{~s}$ (i.e., $x=2,5,15,30,45,60$ ) as function of deposition time.

Table S2. Statistical calculations of $\mathrm{CN}-\mathrm{CM}_{x} \mathrm{M}$ films thickness.

\begin{tabular}{|c|c|c|c|}
\hline Deposition time (s) & $\begin{array}{l}\text { Average thickness of both } \\
\text { sides }(\mu \mathrm{m})\end{array}$ & $\begin{array}{l}\text { Total average } \\
\text { thickness }(\mu \mathrm{m})\end{array}$ & Standard deviation $(\mu \mathrm{m})$ \\
\hline \multirow{4}{*}{2} & 16.8 & & \\
\hline & 16.9 & 16.9 & 0.05 \\
\hline & 16.9 & & \\
\hline & 17.6 & & \\
\hline \multirow[t]{3}{*}{5} & 17.1 & 17.9 & 1.1 \\
\hline & 19.2 & & \\
\hline & 18.5 & & \\
\hline \multirow[t]{3}{*}{15} & 18.5 & 18.6 & 0.1 \\
\hline & 18.7 & & \\
\hline & 19.7 & & \\
\hline \multirow[t]{3}{*}{30} & 18.7 & 18.8 & 0.9 \\
\hline & 18.0 & & \\
\hline & 20.4 & & \\
\hline \multirow[t]{3}{*}{45} & 25.8 & 24.3 & 3.4 \\
\hline & 26.6 & & \\
\hline & 29.2 & & \\
\hline \multirow[t]{3}{*}{60} & 24.0 & 26.6 & 2.6 \\
\hline & 26.6 & & \\
\hline & 27.2 & & \\
\hline \multirow[t]{3}{*}{120} & 22.7 & 25.9 & 2.7 \\
\hline & 27.7 & & \\
\hline & 32.1 & & \\
\hline \multirow[t]{2}{*}{180} & 32.9 & 31.8 & 1.3 \\
\hline & 30.4 & & \\
\hline
\end{tabular}




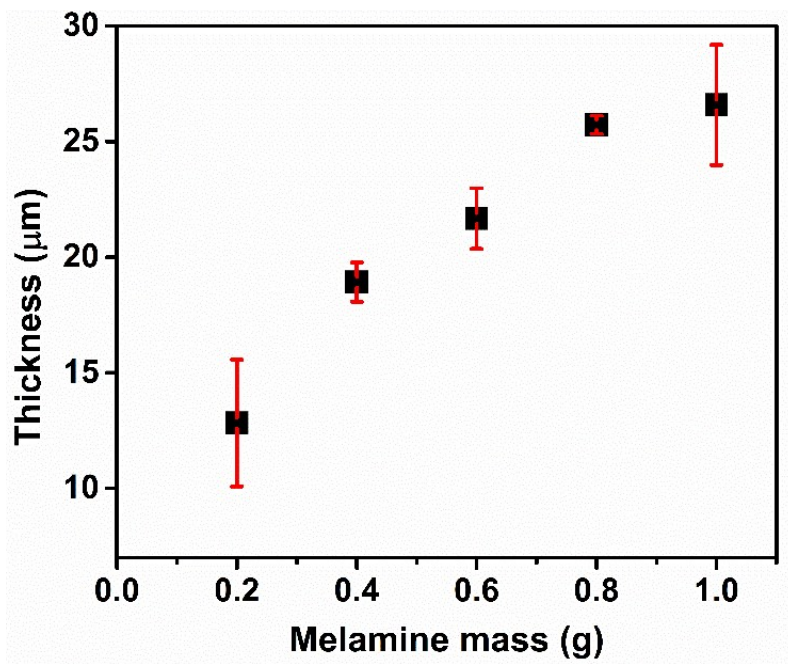

Fig. S11 Film thickness of $\mathrm{CN}-\mathrm{CM}_{60} \mathrm{M}_{y}$ electrodes as function of melamine powder mass in the glass tube during preparation of the electrodes.

Table S3. Statistical calculations of $\mathrm{CN}-\mathrm{CM}_{60} \mathrm{M}_{y}$ films thickness.

\begin{tabular}{|c|c|c|c|}
\hline Melamine mass (g) & $\begin{array}{l}\text { Average thickness of both } \\
\text { sides }(\mu \mathrm{m})\end{array}$ & $\begin{array}{l}\text { Total average } \\
\text { thickness }(\mu \mathrm{m})\end{array}$ & Standard deviation $(\mu \mathrm{m})$ \\
\hline \multirow{4}{*}{0.2} & 10.0 & & \\
\hline & 15.5 & 12.8 & 2.7 \\
\hline & 13.0 & & \\
\hline & 18.2 & & \\
\hline \multirow[t]{3}{*}{0.4} & 18.7 & 18.9 & 0.8 \\
\hline & 19.8 & & \\
\hline & 23.1 & & \\
\hline \multirow[t]{3}{*}{0.6} & 20.5 & 21.7 & 1.3 \\
\hline & 21.4 & & \\
\hline & 26.2 & & \\
\hline \multirow[t]{3}{*}{0.8} & 25.6 & 25.7 & 0.4 \\
\hline & 25.4 & & \\
\hline & 29.2 & & \\
\hline \multirow[t]{2}{*}{1.0} & 24.0 & 26.6 & 2.6 \\
\hline & 26.6 & & \\
\hline
\end{tabular}




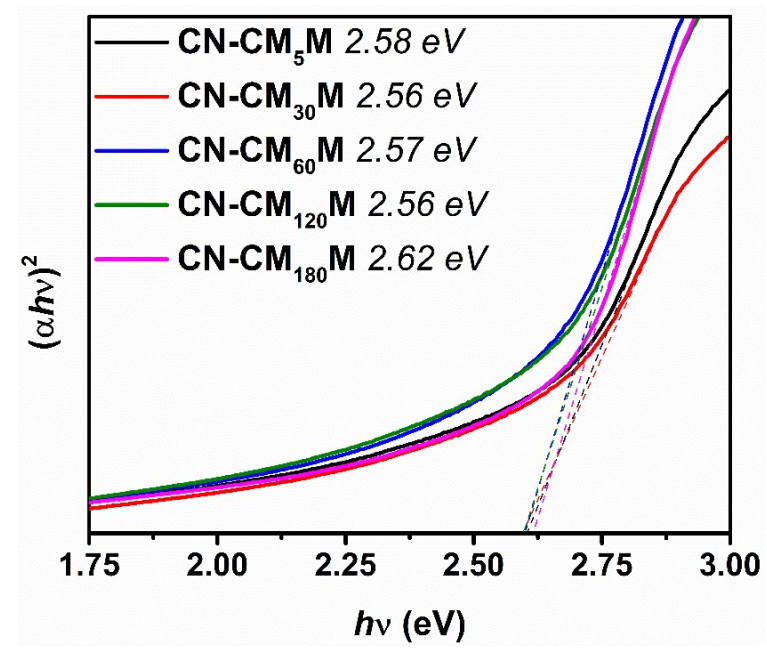

Fig. S12 Tauc plots of $\mathrm{CN}-\mathrm{CM}_{x} \mathrm{M}$ electrodes (direct optical band gap, $E_{\mathrm{g}}$ ).

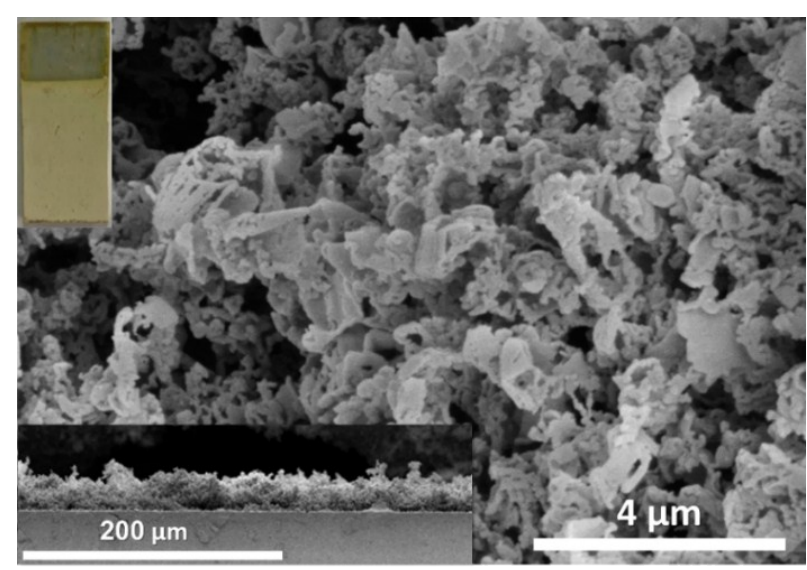

Fig. S13 SEM image of $\mathrm{CN}-\mathrm{CM}_{120} \mathrm{CM}$ electrode (insets: the corresponding digital photo and cross-sectional SEM image).
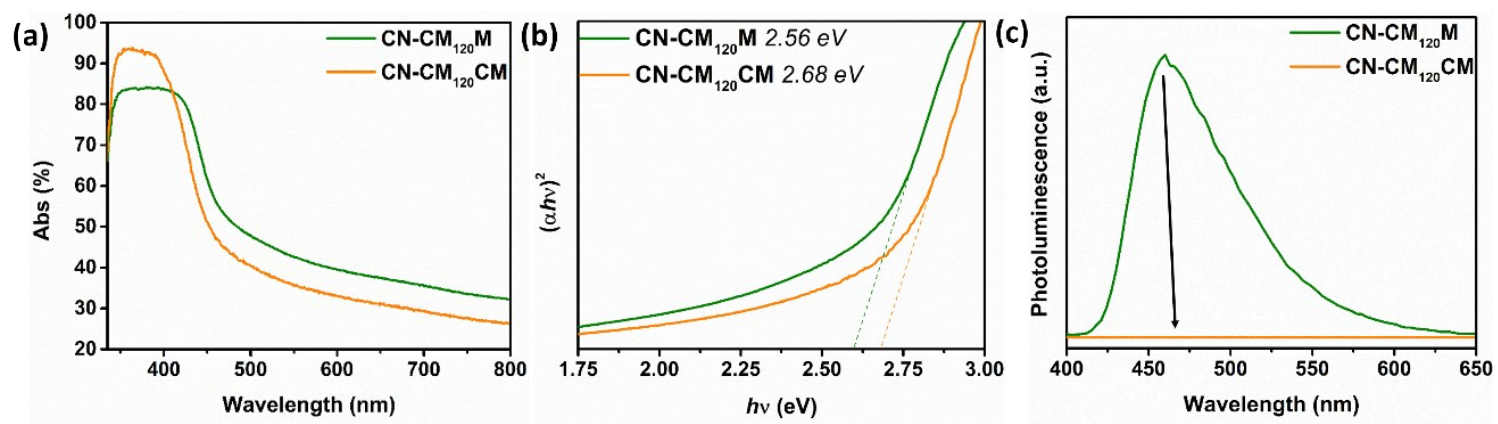

Fig. S14 Optical characterization of $\mathrm{CN}-\mathrm{CM}_{120} \mathrm{CM}$ and $\mathrm{CN}-\mathrm{CM}_{120} \mathrm{M}$ electrodes: (a) UV-Vis absorptance spectra, (b) Tauc plot analysis assuming a direct $E_{\mathrm{g}}$, and (c) photoluminescence spectra $\left(\lambda_{\mathrm{ex}}=380 \mathrm{~nm}\right)$. 

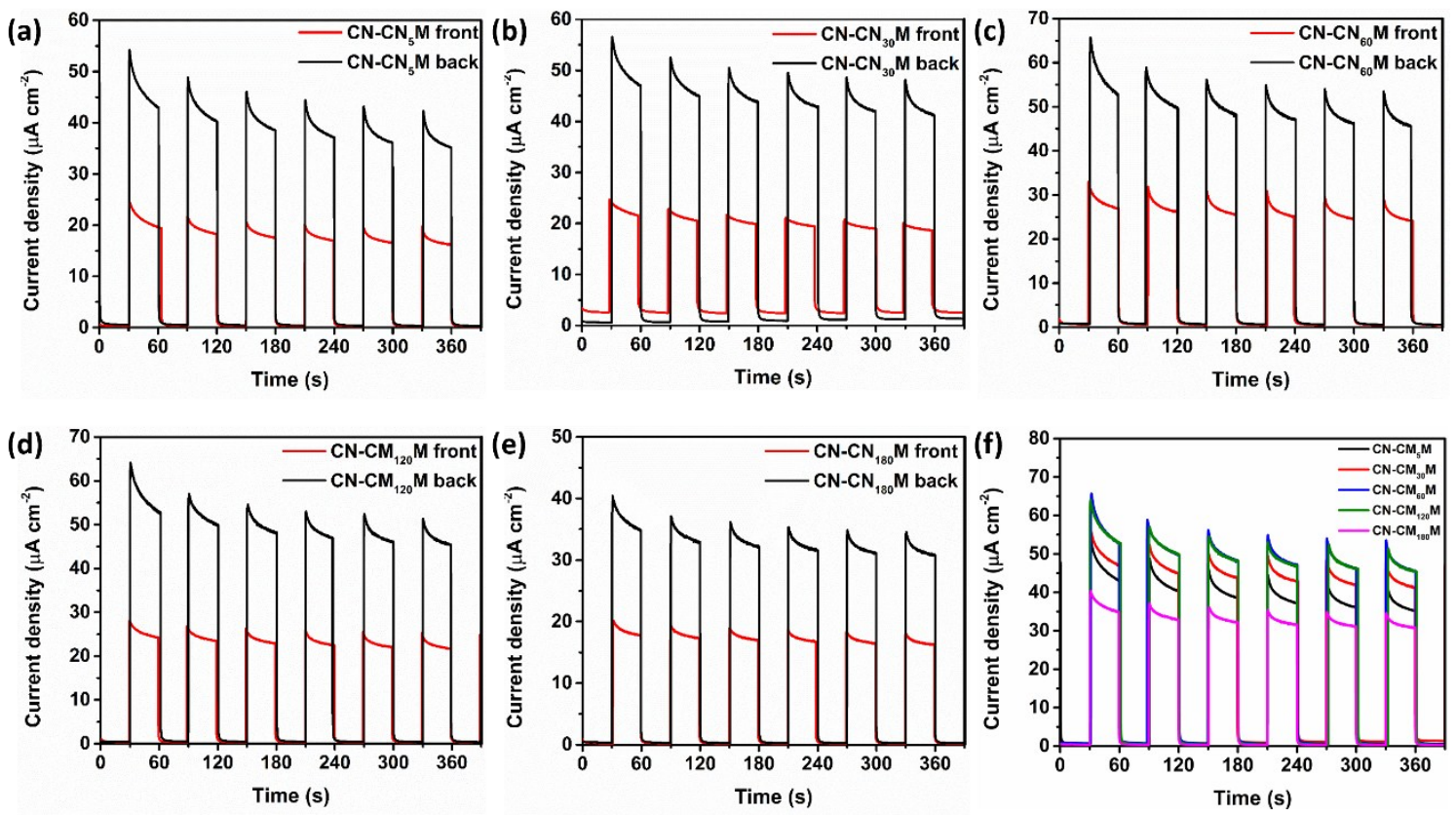

Fig. S15 Photocurrent densities at $1.23 \mathrm{~V}$ vs. RHE in $0.1 \mathrm{M} \mathrm{KOH}$ of (a) $\mathrm{CN}_{-} \mathrm{CM}_{5} \mathrm{M}$, (b) $\mathrm{CN}-$ $\mathrm{CM}_{30} \mathrm{M}$, (c) $\mathrm{CN}-\mathrm{CM}_{60} \mathrm{M}$, (d) $\mathrm{CN}-\mathrm{CM}_{120} \mathrm{M}$, and (e) $\mathrm{CN}_{-} \mathrm{CM}_{180} \mathrm{M}$ electrodes under front- and backillumination ( 1 sun), and (f) comparison of $\mathrm{CN}-\mathrm{CM}_{x} \mathrm{M}$ electrodes under back illumination ( 1 sun). 


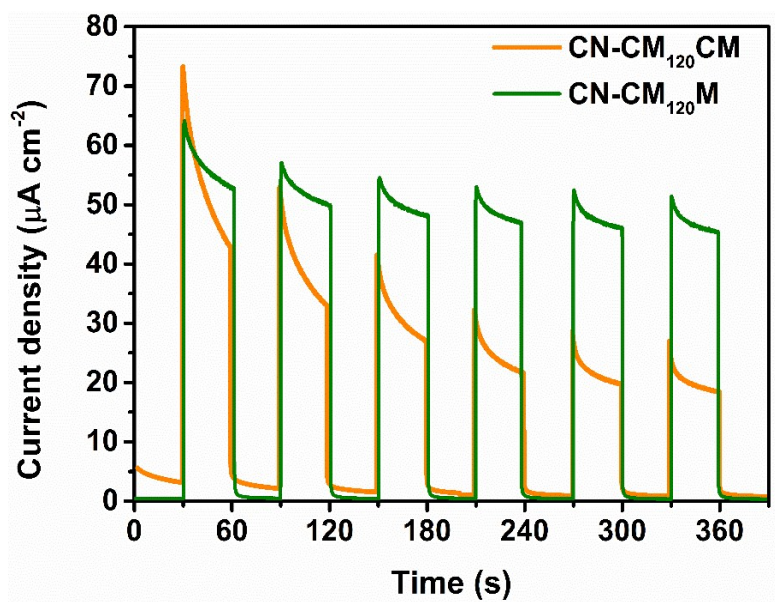

Fig. S16 Photocurrent densities of $\mathrm{CN}-\mathrm{CM}_{120} \mathrm{CM}$ and $\mathrm{CN}-\mathrm{CM}_{120} \mathrm{M}$ electrodes at $1.23 \mathrm{~V}$ vs. RHE in $0.1 \mathrm{M} \mathrm{KOH}$ under back-illumination (1 sun).

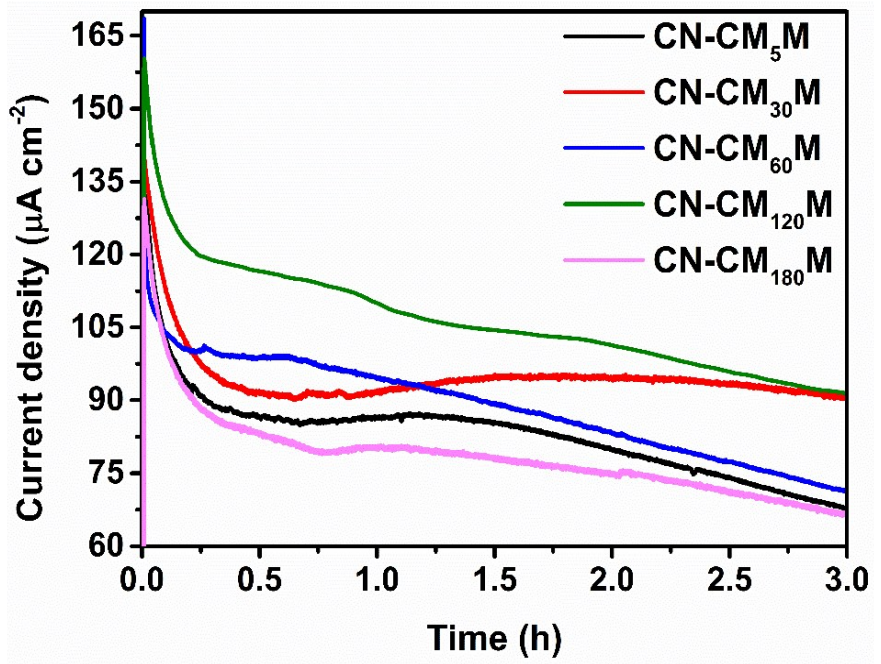

Fig. S17 Photocurrent stability of $\mathrm{CN}-\mathrm{CM}_{x} \mathrm{M}$ electrodes at $1.23 \mathrm{~V}$ vs. RHE in $0.1 \mathrm{M} \mathrm{KOH}$ aqueous solution containing 10\% v/v TEOA upon continuous back-side illumination (1 sun). 

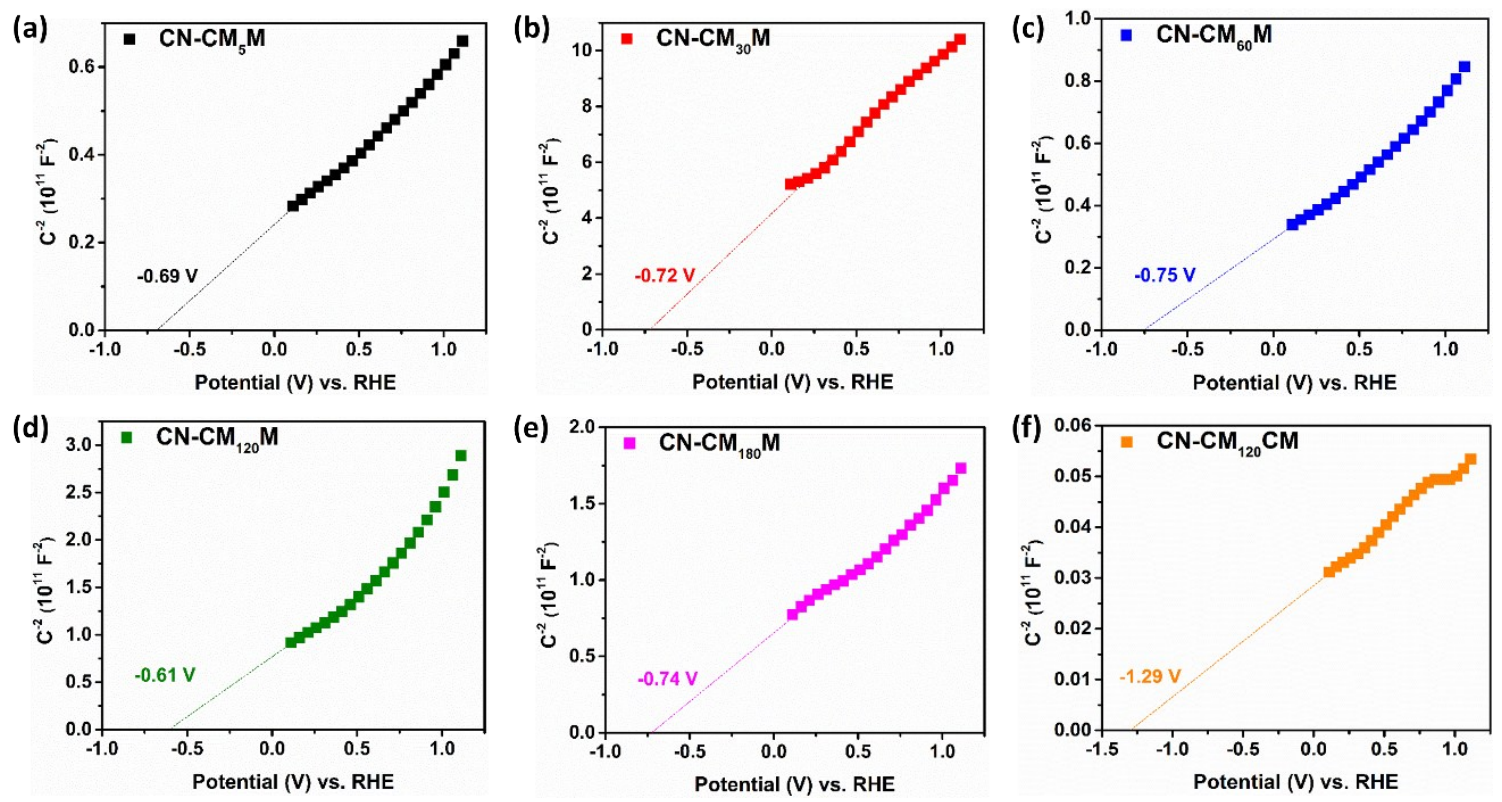

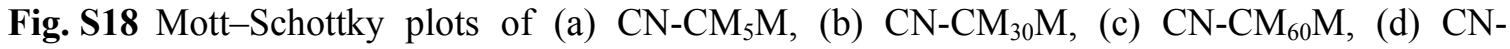
$\mathrm{CM}_{120} \mathrm{M}$, (e) $\mathrm{CN}-\mathrm{CM}_{180} \mathrm{M}$, and (f) $\mathrm{CN}-\mathrm{CM}_{120} \mathrm{CM}$ electrodes.

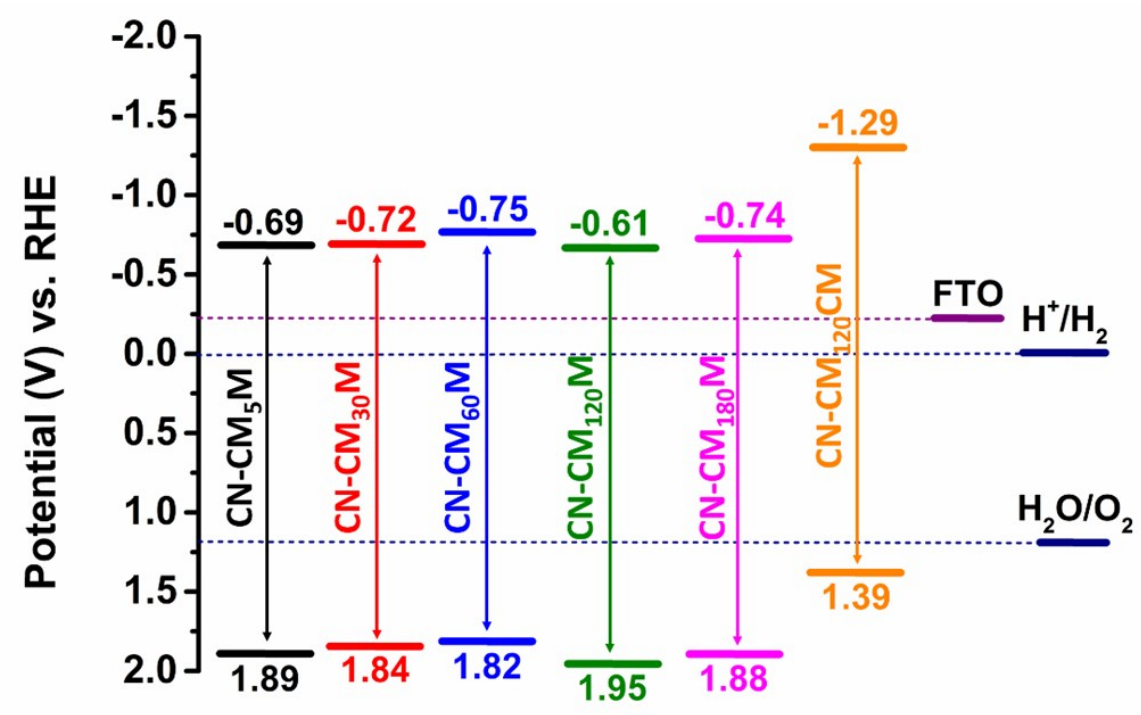

Fig. S19 Proposed energy level diagram of $\mathrm{CN}-\mathrm{CM}_{x} \mathrm{M}$ and $\mathrm{CN}-\mathrm{CM}_{120} \mathrm{CM}$ electrodes with respect to water redox reactions. 


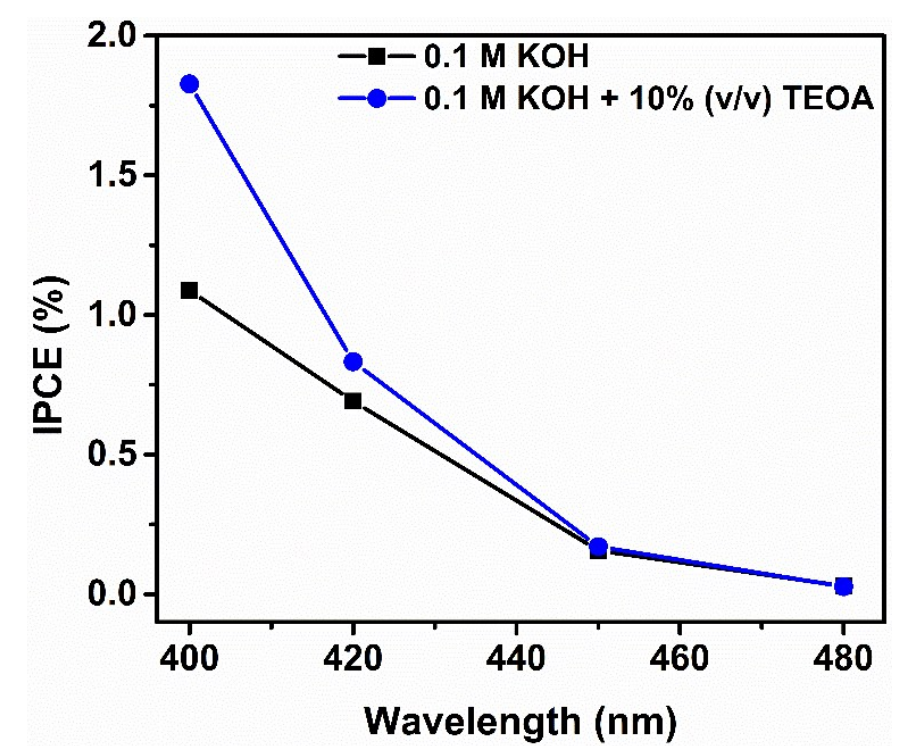

Fig. S20 IPCE measurements of $\mathrm{CN}-\mathrm{CM}_{120} \mathrm{M}$ electrode in $0.1 \mathrm{M} \mathrm{KOH}$ aqueous solution with and without $10 \% \mathrm{v} / \mathrm{v}$ TEOA upon 1 sun illumination.
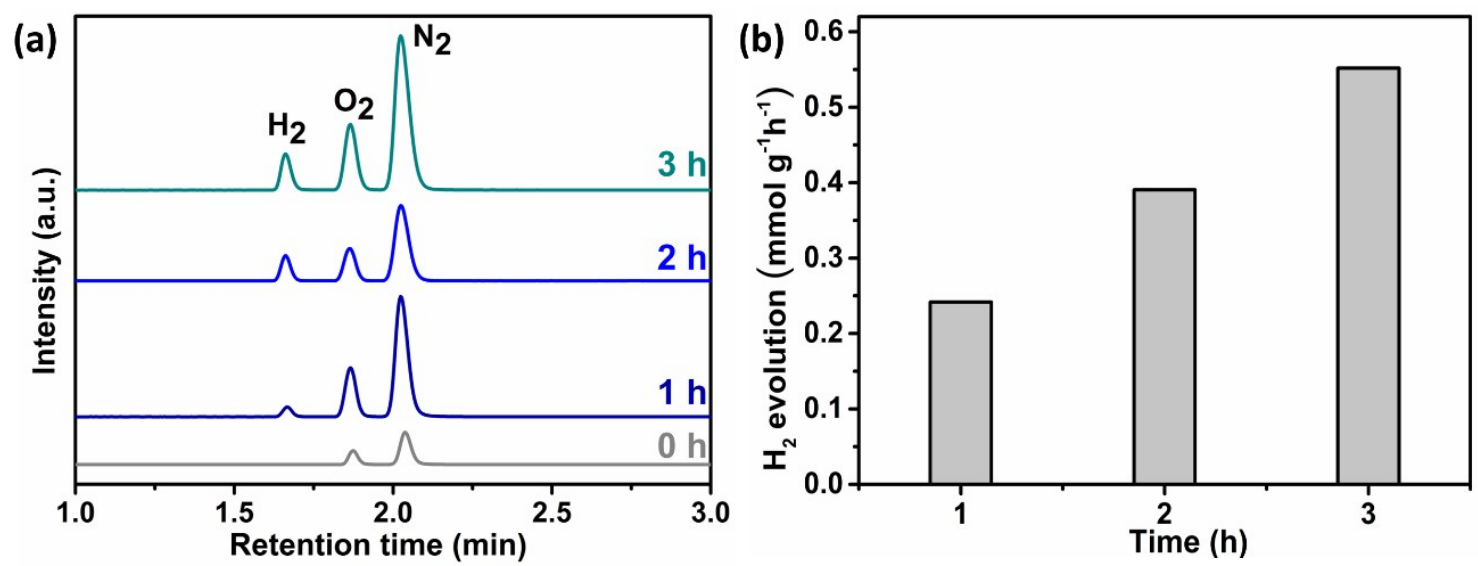

Fig. S21 (a) Gas chromatograph of $\mathrm{CN}-\mathrm{CM}_{120} \mathrm{M}$ as the photoelectrocatalyst biased at $1.23 \mathrm{~V} v \mathrm{~s}$. RHE, under constant 1 sun illumination, and (b) $\mathrm{H}_{2}$ production rates of $\mathrm{CN}-\mathrm{CM}_{120} \mathrm{M}$ in $0.1 \mathrm{M} \mathrm{KOH}$ containing $10 \%(\mathrm{v} / \mathrm{v})$ TEOA. 